\title{
WORK COSTS AND NONCONVEX PREFERENCES IN THE ESTIMATION OF LABOR SUPPLY MODELS
}

\author{
Bradley T. Heim \\ Bruce D. Meyer \\ Working Paper 9429 \\ http://www.nber.org/papers/w9429
NATIONAL BUREAU OF ECONOMIC RESEARCH
1050 Massachusetts Avenue
Cambridge, MA 02138
January 2003

We would like to thank Joseph Altonji, Soren Blomquist, Richard Blundell, Jerry Hausman, Thomas Kniesner, Thomas MaCurdy, Rosa Matzkin and Christopher Taber for valuable conversations, and seminar participants at Duke University, the University of Michigan, the NBER Public Economics Meetings, Stanford University, the University of California, San Diego, and the 2002 Transatlantic Public Economics Seminar for their comments. The views expressed in this paper are those of the authors and not necessarily those of the National Bureau of Economic Research.

(C) 2003 by Bradley T. Heim and Bruce D. Meyer. All rights reserved. Short sections of text, not to exceed two paragraphs, may be quoted without explicit permission provided that full credit, including $(\mathcal{O}$ notice, is given to the source. 
Work Costs and Nonconvex Preferences in the Estimation of Labor Supply Models

Bradley T. Heim and Bruce D. Meyer

NBER Working Paper No. 9429

January 2003

JEL No. D12, J22

\begin{abstract}
We first critique the manner in which work costs have been introduced into labor supply estimation, and note the difficulty of incorporating a realistic rendering of the costs of work. We then show that, if work costs are not accounted for in the budget and time constraints in a structural labor supply model, they will be subsumed into the data generating preferences. We show that even if underlying preferences over consumption and leisure are convex, the presence of unobservable work costs can make these preferences appear nonconvex. Absent strong functional form assumptions, these work costs are not identified in data commonly used for labor supply estimation. However, we show that even if work costs cannot be separately identified, under plausible conditions, policy relevant calculations such as estimates of the effect of tax changes on labor supply and deadweight loss calculations, are not affected by the fact that estimated preferences incorporate work costs.

Bradley T. Heim

Department of Economics

Duke University

305 Social Sciences Building

Box 90097

Durham, NC 27708

bheim@econ.duke.edu

Bruce D. Meyer

Department of Economics and

Institute for Policy Research

Northwestern University

Evanston, IL 60208

and NBER

bmeyer@northwestern.edu
\end{abstract}




\section{Introduction}

In empirical studies, economists typically assume that preferences are convex. Convexity of preferences yields a number of simplifying results, among them single valued demand functions. As a result, estimation often begins by positing a simple functional form for a demand function, without being too concerned about the underlying preference relation that generates the demand function. Further, as long as the estimated demand function satisfies Slutsky negativity and symmetry, one is guaranteed that there exists a convex preference ordering consistent with such a demand function. ${ }^{1}$ Thus, making the assumption of convex preferences greatly simplifies any estimation procedure.

In most economic applications, the assumption of convex preferences is innocuous. When budget sets are linear, the choice behavior of an individual with nonconvex preferences is identical to the choice behavior of an individual with convex preferences that are created by convexifying the nonconvex indifference curves. As a result, no economically meaningful part of the indifference curve is lost by assuming that preferences are convex.

When budget constraints are nonlinear, however, all parts of preferences can become economically meaningful. When budget constraints are nonlinear and convex, for example, there are nonconvex preferences for which utility can be maximized on the interior of the convex hull of an indifference curve. ${ }^{2}$ Hence, in this setting, a convexified indifference curve does not yield the same choice behavior as the nonconvex indifference curve, and so one cannot assume that preferences are convex without ruling out some choice behavior.

In spite of this, in structural labor supply estimation in the presence of nonlinear budget constraints, the assumption of convex preferences has been invoked in virtually all estimation methods. For example, in the various local linearization methods, the assumption of convex preferences is used to reduce the entire labor supply decision down to a marginal decision that is determined by the after tax wage and nonlabor income associated with the budget constraint segment on which the individual is observed. ${ }^{3}$ In Hausman (1985), convex preferences yield a computationally easy method of identifying the utility maximizing point on the nonlinear budget constraint, and facilitate the straightforward setup of the likelihood function. ${ }^{4}$ Finally, the method proposed in MaCurdy, Green and Paarsch (1990), strictly convex preferences yield an implicit function that can be used to solve for optimal hours on a differentiable approximation to the budget constraint as a function of the stochastic elements, which is then inverted and used as an argument in the likelihood function. ${ }^{5}$

As we argue in Heim and Meyer (2002), a possible reconciliation of the findings in previous studies, which often found estimates of labor supply parameters either inconsistent (or constrained to be consistent) with economic theory, is that the data used in the various

\footnotetext{
${ }^{1}$ See Hurwicz and Uzawa (1971).

${ }^{2}$ It is easy to verify, however, that if the budget constraint is nonlinear and concave, then utility cannot be maximized on the interior of the convex hull of an indifference curve. Essentially, in a labor supply setting, maximization on the interior of the convex hull may occur on portions of the budget constraint in which the after tax wage decreases as hours increase, and not when the after tax wage increases as hours increase.

${ }^{3}$ See Hall (1973) for an explanation of this.

${ }^{4}$ For an explanation of the Hausman method, see Hausman (1985). For a discussion of the use of convexity in the Hausman method, see the previous chapter.

${ }^{5}$ See MaCurdy et al. (1990) for an exposition of the MaCurdy method of using a differentiable budget constraint to estimate labor supply parameters.
} 
estimation methods were generated by the maximization of nonconvex preferences on the nonlinear budget constraint. We further show that the standard methods used to estimate labor supply in this setting cannot be adapted to allow for the estimation of parameters consistent with nonconvex preferences, and suggest a method that can. Why, then, should one consider the possibility that preferences may be nonconvex in the setting of labor supply?

One possibility is that underlying preferences over consumption and leisure are nonconvex. Preferences that are nonconvex may still satisfy a number of other weaker assumptions, including being complete, reflexive, transitive, continuous, monotonic and locally nonsatiated. It may be that preferences simply do not satisfy convexity, even if they satisfy the other conditions.

Another possibility is that the time frame over which the data are collected is not sufficiently long for convexity of preferences to apply. As noted in Mas-Collel, Whinston, and Green (1995) and Varian (1992), the standard justification for the assumption of convex preferences is that, even though one may not want to consume two goods together at the same time, one would prefer a mix of goods over a longer period of time. In the case of most consumption goods, the time frame necessary for this averaging argument to apply is probably short; perhaps a week or a month is a sufficiently long period of time. However, in the case of a consumption-hours of work choice, the time frame needed for the averaging argument to apply may be quite long, perhaps even a lifetime. As a result, it may be in the monthly or yearly time frame that is conventionally used in labor supply estimation, convexity of preferences does not hold.

Finally, in this paper, we show that, even if underlying preferences over consumption and leisure are convex in the period of analysis, what we call data generating preferences or observable preferences in a structural labor supply model may be nonconvex, because they may be composed of more than just an individual's underlying preferences. This point derives from the fact that an individual's consumption and leisure usually cannot be observed, and so must be inferred from monetary outlays (or income) and hours of work. As a result, labor supply models are usually written in terms of hours of work and monetary outlays.

The usual assumption is that all income or outlays are devoted to consumption and that all non-compensated hours are leisure time. If these assumptions are correct, it is obvious that if underlying preferences are convex, data generating preferences over monetary outlays and hours of work would also be convex, and hence the assumption underlying the aforementioned models would be correct. However, we argue that, in actuality, individuals face both monetary and time costs of work when making their choice of labor supply, and that these costs of work vary with the number of hours that the individuals work. These work costs can be sizable, with time work costs likely comprising the larger share. The presence of such work costs may, for example, help to explain the bunching of hours at certain daily, weekly, monthly, and annual levels that is often found in data. Despite this situation, in structural labor supply estimation, work costs have either been left out of the model or treated in a simplistic manner.

We show, however, that in making such a simplification, data generating preferences over monetary outlays and hours of work will not simply consist of underlying preferences, but will also be affected by the shape of these cost of work functions. We then establish 
a necessary condition on the form of the costs of work function, under which observable preferences will be nonconvex.

We show that, under certain assumptions on the form of underlying preferences, one can test for the presence of work costs by examining the shape of observable preferences if work costs satisfy certain shape restrictions. However, what we would prefer is separate identification of utility and costs of work functions, and we show that the component parts of observable preferences are not separately identified absent functional form assumptions. Finally, we show that, despite the lack of separate identification of the constituent parts of observable preferences, deadweight loss calculations, and some policy simulations, may still be performed.

This paper proceeds as follows. In Section 2, we critique the manner in which work costs have been introduced into labor supply estimation, and note the difficulty of incorporating a realistic rendering of the costs of work. In Section 3, we show that even if one does not believe that underlying preferences are convex, the presence of unobservable work costs can make observable preferences nonconvex. In Section 4, we show that, absent functional form assumptions, separate identification of utility and work cost functions in structural labor supply estimation is not possible. In Section 5, however, we show that, even if work costs cannot be separately identified, policy relevant calculations, such as estimates of the effect of tax changes on labor supply, or deadweight loss calculations, under plausible conditions are not affected by the fact that estimated preferences incorporate work costs. Section 6 concludes.

\section{A Critical Review of Previous Models of Work Costs}

The idea that individuals incur some costs while working is not a new one. In fact, several papers have incorporated costs of work into labor supply estimation. However, the treatment of costs of work has been relatively simplistic. In most cases, the empirical studies that have incorporated costs of work have done so by specifying these costs as a fixed cost of working any positive number of hours.

In the discussion that follows, we review the ways in which work costs have been introduced into various types of empirical labor supply models. This research has found that the introduction of a fixed cost of work into empirical specifications has had a marked effect on estimated parameters. We then argue, however, that the costs of work are not fixed, but vary in a complex way with the number of hours an individual works. As such, incorporating only a fixed cost of work misspecifies the decision problem that the individual faces.

\subsection{Previous Empirical Work}

Beginning with Cogan (1980), Hanoch (1980) and Hausman (1980), several studies have incorporated time and/or money costs of work into their empirical specification. Almost all of these papers have modelled the costs of work as a fixed cost of entry into the labor force.

Cogan (1981), for example, estimates a maximum likelihood model of labor force participation, wages, and hours worked, that incorporates fixed costs of work, but not the tax 
system. Estimating the model on married women, he finds that the estimated costs of work are significant.

Considering child care costs, Blau and Robins (1988) incorporate child care costs into the time and money budget constraints of married women. Estimating a multinomial logit model, they find that child care costs significantly affect household labor supply. Ribar (1992) extends Blau and Robins, and finds that child care costs significantly affect the labor force participation decision of women.

In a discrete choice model of labor supply analyzing the effects of AFDC-UP, Hoynes (1996) parameterizes the budget constraint that a family would face under various employment and hours of work combinations for husbands and wives. She then adds monetary fixed costs of labor market entry to her model, and finds that they enter significantly.

The incorporation of fixed costs into labor supply estimation has also extended to the piecewise linear budget constraint literature. Fixed costs of working are incorporated in Hausman's (1980) study of the labor force participation of women, as well as in Bourguignon and Magnac (1990). Both of these studies find that there are significant fixed costs of work.

\subsection{Critique of Previous Work Cost Specifications}

As noted above, previous empirical studies have invariably incorporated the costs of work, if they were incorporated at all, as a fixed cost of labor market entry.

Depending on the time frame which the data cover, a fixed cost of working may be a reasonable approximation to the actual costs that a worker faces. Cogan (1981), noted this, and argued that if a lump sum fixed cost specification is used, one should use data corresponding to the frequency in which this fixed cost is incurred. Thus, if one were estimating a model of the daily choice of labor supply, a fixed cost specification might be plausible, since the costs incurred are plausibly invariant whether one decides to work one hour or eight. This type of strategy is employed by Blank (1988), who incorporates hourly and weekly fixed costs of work into her specification.

Empirical labor supply studies, however, almost invariably consider a time frame of a month or longer, and usually use annual data. A consideration of the major components of the costs of work, including commuting time, transportation costs, costs associated with the stress of work and the time preparing for and recovering from work, and training costs, makes explicit that annual work costs likely vary with the number of annual hours worked in a complex way. As such, if one is using monthly or yearly data, a fixed cost specification will likely not be a good approximation.

Transportation costs are incurred each day of work and take the form of both a monetary cost (including paying for gas, subway or bus fare, parking and tolls, and so on) and a time cost (the time to get to and from work each day). The monetary costs may consist of a fixed cost, and costs linear in the number of days worked, or there may be volume discounts available (for example, in the purchase of monthly transit or parking passes). The time costs, on the other hand, are probably roughly linear in the number of days worked. Estimates of time spent commuting in several countries range from about seven to ten percent of market work time (Juster and Stafford, 1991). Child care and closting costs are likely to be concave in annual hours worked, but are not as large on average as commuting costs. 
Most jobs also require some form of training, either before taking the job or in an ongoing manner. In cases in which training is paid for by the employer, the training does not constitute an explicit monetary expense for the worker ${ }^{6}$, but may involve a time cost if the time involved in taking classes or doing homework associated with such training is not compensated. In other cases, the employee must pay for training, in which case both monetary and time costs are incurred. These costs may be fixed, or may vary with the number of hours worked.

It is also true that there may be economies to working a schedule similar to other people. When this is done, car pools may be used, less expensive child care is available, and so on. This would suggest that costs of work are greater if one works a number of hours away from full or part time.

Finally, there are large time costs that are incurred in preparing for, and recovering from, work each day. In addition, there also are likely to be costs of having the additional responsibilities and complications in one's life that often come with work. The stress and emotional costs of work figure prominently in the psychology and sociology literatures, for example in Lee and Ashforth (1996) and Morris and Feldman (1996). Further, Hobfoll (1989) conceptualizes stress as leading to a loss of resources, including time and money. These types of costs are likely to be large relative to explicit money costs, and it is likely that these costs are concave in the number of monthly or annual hours that individuals work, due to the increased ease in dealing with work if one has a daily and weekly routine. The presence and likely substantial magnitude of such costs also illustrates that a large part of the costs of work could be thought of as either time costs or aspects of work that are more commonly thought of as a feature of preferences. Thus, conceptually it is hard to distinguish time costs of work from preferences.

Thus, both time and monetary work costs are substantial, and time work costs seem to be large. In addition, in contrast to previous renderings of the costs of work, it seems clear that work costs vary with the number of monthly or annual hours an individual works. Furthermore, since portions of work costs may also be linear or concave functions of the number of days or weeks that an individual works, it is likely that a fixed cost specification is a bad approximation when monthly or yearly labor supply is being studied.

A more complex form of work costs may also help to explain the bunching of hours that is often found in survey data. If work costs were simply a fixed cost, and individuals preferences were convex over all positive annual hours of work, then we would expect there to be little bunching around any particular level of hours ${ }^{7}$. However, there tends to be noticeable amount of bunching of the data around certain levels of hours. For example, in the data used in Hausman (1981), there is considerable bunching around 2000 annual hours and 40 weekly hours. Among other things, the presence of work cost that vary with the number of hours that an individual works may help to explain why individuals tend to choose certain levels of hours on a daily, weekly, monthly, and annual basis.

\footnotetext{
${ }^{6}$ Though the worker often implicitly must pay for the training in the form of lower wages.

${ }^{7}$ Except, perhaps, around convex kinks in budget constraints due to the structure of the income tax. However, this type of bunching is often not pronounced, and thus cited as the reason for including measurement error in a stochastic specification when using the Hausman method to estimate labor supply parameters. See, for example, the discussion in Blundell and MaCurdy (1999), p. 1633.
} 


\subsection{Infeasibility of Explicit Incorporation of the Costs of Work}

Clearly, given the above discussion, incorporating only a fixed cost of work when the time frame under analysis is a month or more assumes away the complex manner in which the costs of work vary with the number of hours that a person works. Explicitly characterizing the complex form of these costs in structural estimation of labor supply would clearly be desirable. In what follows, however, we note that many practical problems make this approach infeasible.

To illustrate this point, suppose that individuals faced only monetary costs of work, and that a researcher knew the form of the cost of work function, which will be denoted $F_{1}(h)$, where $h$ denotes the number of hours the individual works ${ }^{8}$. Let the individual's after tax budget constraint, ignoring the costs of work, be a function of their gross wage, $W$, their nonlabor income, $Y$, and the number of hours they work, $h$. Denote this budget constraint as $f(W, Y, h)$. Letting $C$ denote consumption, the individual's actual budget constraint, when both the tax system and work costs are incorporated, is thus

$$
C+F_{1}(h) \leq f(W, Y, h) .
$$

Letting $w$ denote the net wage and $y$ denote virtual income associated with a segment of a nonlinear budget constraint, given a specification for a labor supply function, $h(w, y)$, and under the assumption that preferences are convex, one could in theory construct the budget constraint above for each individual in the data, and use an already existing method to estimate labor supply parameters in the presence of nonlinear budget constraints.

In practice, however, such an approach will run into data limitations. Although most monetary costs of work described above are theoretically observable, very few of the surveys commonly used for labor supply estimation collect data about work costs, and none ask questions about all of the possible components of work costs.

Furthermore, the above discussion only considers the monetary costs of working. We expect that time costs of work incurred by individuals are more important than monetary costs. If we denote the time costs of working as $F_{2}(h)$, the individual's time constraint is now

$$
L \leq \bar{H}-F_{2}(h)-h,
$$

where $L$ denotes leisure and $\bar{H}$ is the time endowment. Explicitly characterizing these costs results in an even more complicated budget constraint and even more difficult data problems, since it is especially unlikely that accurate data can be collected on the some of the time costs of work, like the time required to prepare for or unwind from work.

Hence, it is clear why most labor supply specifications have only incorporated a fixed cost of work, or have ignored work costs completely. However, work costs do exist, and in the next section we show that if work costs are not accounted for in the budget and time constraints, then the assumed data generating preferences in such an approach will not be the maximization of the individuals' underlying preferences over consumption and leisure

\footnotetext{
${ }^{8}$ This setup is generalized to a case in which individuals have a choice among various modes of transportation, child care, and so on, with each mode having its own time and money cost schedules, in Appendix B. In this case, the results that follow generalize to this setting if one replaces $F_{1}(h)$ and $F_{2}(h)$ with $F_{1}(O, h)$ and $F_{2}(O, h)$, respectively, and makes straightforward changes to each of the propositions.
} 
subject to the tax law generated budget constraint, but will rather be the maximization of those preferences augmented by the work cost functions. We then show that the preferences that result will likely be nonconvex, and explore the implications of this on the choice of an estimation method.

\section{How Work Costs Can Make Preferences Appear Non- convex}

In the previous section, we argued that if the costs of work vary with the number of hours an individual works, then the budget constraint generated by the tax tables does not represent the actual budget constraint that workers face, and incorporating only a fixed cost into an estimation procedure will be inadequate.

In this section, we demonstrate that, although work costs would customarily be accounted for in the budget and time constraints, for any maximization problem of utility over consumption and leisure, subject to budget and time constraints that incorporate work costs, there exists an equivalent maximization problem in which a function over monetary outlays and hours of work, which incorporates underlying preferences over consumption and leisure and time and money work costs, is maximized subject to the statutory budget constraint. We will refer to this function as a composite utility function, and to the preferences it represents as observable preferences. This result implies that if one estimates preferences using only tax tables to specify the budget constraint, but that individuals actually face time and/or monetary work costs when choosing hours of work, then one is thus attempting to estimate data generating preferences with the costs of work incorporated therein.

We then examine what conditions on the costs of work will lead observable preferences to be nonconvex. It turns out that, given the variety of possible shapes for the costs of work, nonconvexity of observable preferences is plausible. Thus, if one is using tax tables to specify the budget constraint, one must be careful about the assumptions that one makes about the form of the utility function, and allow for the possibility that preferences are nonconvex.

\subsection{Incorporation of Work Costs into Utility Functions}

In this section, we show that every utility maximization problem in which work costs are factored into the budget and time constraints has an equivalent formulation where these work costs are subsumed into observable preferences, and for which the optimal hours choice is the same.

First, let $O$ denote total monetary outlays, the sum of outlays on the composite consumption good and costs of work. The following proposition demonstrates that given a problem in which the consumer maximizes utility over consumption and leisure subject to a budget constraint that incorporates tax laws and monetary costs of work, and a time constraint that incorporates time costs of work, there exists a problem involving the maximization of a composite utility function over outlays and hours of work that incorporates preferences and time and monetary work costs subject to only the tax law generated budget constraint, and for which the optimal hours of work is the same. 
Proposition 1 For every consumer problem in which a utility function, $U(C, L)$, is maximized subject to an arbitrary budget constraint that incorporates monetary costs of work, $F_{1}(h)$, and a time constraint that incorporates time costs of work, $F_{2}(h)$, there exists an equivalent problem in which a composite utility function, $\widetilde{U}(O, h)$, that incorporates preferences and time and monetary work costs is maximized subject to only the budget constraint, and for which the optimal hours choice is the same.

Proof. Consider a consumption - leisure choice problem subject to a general budget constraint that incorporates money costs of work, and an hours constraint that incorporates time costs of work,

$$
\begin{aligned}
& \max _{C, L, h} U(C, L) \\
\text { s.t. } C+F_{1}(h) \leq & f(W, Y, h, \theta) \\
h+F_{2}(h)+L \leq & \bar{H},
\end{aligned}
$$

where $\theta$ denote tax parameters, and all other variables are as defined previously.

Define $O \equiv$ money outlays $\equiv C+F_{1}(h)$. Using $C=O-F_{1}(h)$, and substituting the time constraint in for $L$, we can rewrite (3) as

$$
\begin{array}{ll} 
& \max _{O, h} U\left(O-F_{1}(h), \bar{H}-h-F_{2}(h)\right) \\
\text { s.t. } O \leq & f(W, Y, h, \theta) .
\end{array}
$$

Define $\widetilde{U}(O, h)=U\left(O-F_{1}(h), \bar{H}-h-F_{2}(h)\right)$. Then we have

$$
\begin{array}{r}
\max _{O, h} \widetilde{U}(O, h) \\
\text { s.t. } O \leq f(W, Y, h, \theta) .
\end{array}
$$

Since the problems are equivalent, if $\left(C^{*}, L^{*}\right)$ solves $(3)$, then $\left(O^{*}, h^{*}\right)$, where $O^{*}=$ $C^{*}+F_{1}\left(h^{*}\right)$ and $h^{*}+F_{2}\left(h^{*}\right)=\bar{H}-L^{*}$, solves (5).

The above proposition also holds if the worker faces only monetary (or only time) costs of work. To see this, simply set $F_{2}(h)$ (or $\left.F_{1}(h)\right)$ to 0 .

The setting in the proposition above is clearly a simplified one, in which $F_{1}(h)$ and $F_{2}(h)$ are exogenous to the workers choice, whereas workers obviously have some choices to make regarding how they get to work, what type of training they take, what form of child care their children receive, and so on. However, in Appendix A, we present a generalization of this proposition, in which individuals can choose among various modes of transportation, child care, and so on, with each mode having its own time and money cost schedules.

The following proposition demonstrates that the converse of the above proposition is also true, that for any problem in which a consumer maximizes a composite utility function, which incorporates preferences and time and monetary work costs, subject to a tax law generated budget constraint, there exists an equivalent problem in which the consumer maximizes utility over consumption and leisure subject to a budget constraint that incorporates the tax laws and monetary costs of work, and a time constraint that incorporates time costs of work, and for which the hours choice is the same. 
Proposition 2 For every consumer problem in which utility over outlays and hours of work that incorporates the time and money costs of work, $\widetilde{U}(O, h)$, is maximized subject to a budget constraint, there exists an equivalent problem in which utility over consumption and leisure, $U(C, L)$, is maximized subject to a budget constraint that incorporates monetary costs of work and a time constraint that incorporates time costs of work, and for which the hours choice is the same.

Proof. Using the notation above, start with

$$
\begin{array}{r}
\max _{O, h} \widetilde{U}(O, h) \\
\text { s.t. } O \leq f(W, Y, h, \theta) .
\end{array}
$$

Using that $O=C+F_{1}(h)$, and $L=\bar{H}-h-F_{2}(h)$, define $g(h)=F_{2}(h)+h$. Then $\bar{H}-L=g(h) \Longrightarrow h=g^{-1}(\bar{H}-L)$. Thus, (6) now becomes

$$
\begin{aligned}
& \max _{C, L, h} \widetilde{U}\left(C+F_{1}\left(g^{-1}(\bar{H}-L)\right), g^{-1}(\bar{H}-L)\right) \\
\text { s.t. } C+F_{1}(h) \leq & f(W, Y, h, \theta) \\
L= & \bar{H}-h-F_{2}(h) .
\end{aligned}
$$

Defining $\bar{U}(C, L)=\widetilde{U}\left(C+F_{1}\left(g^{-1}(\bar{H}-L)\right), g^{-1}(\bar{H}-L)\right)$ yields the result.

Since the problems are equivalent, if $\left(O^{*}, h^{*}\right)$ solves $(6)$, then $\left(C^{*}, L^{*}\right)$, where $C^{*}=$ $O^{*}-F_{1}\left(h^{*}\right)$ and $L^{*}=\bar{H}-h^{*}+F_{2}\left(h^{*}\right)$, solves $(7)$.

Since these two maximization problems are equivalent, an individual maximizing their underlying utility function subject to budget and time constraints that incorporate work costs can also be viewed as maximizing a composite utility function which subsumes those work costs, subject only to a tax law generated budget constraint. As such, a data generating process involving the maximization of preferences subject to budget and time constraints that incorporate work costs, has an equivalent data generating process in which individuals maximize observable preferences which subsume the work costs, subject only to a tax law generated budget constraint.

Further, if some work costs are observable and accounted for in the budget constraint, and other work costs are unobservable, it is a simple extension of the propositions above to show that if the budget constraint is specified using the tax law generated budget constraint and the observable work costs, then the unobservable work costs will be incorporated into the estimated preferences.

These results are analogous to a result in Feenstra (1986) in showing how some element of an individual's budget constraint could be equivalently viewed as affecting the individual's preferences, or vice versa. In that paper, Feenstra demonstrates that a model in which real money balances are an argument of the utility function is functionally equivalent to a model in which liquidity costs enter into the budget constraint. Similarly, Fuhrer (1990) and others have argued that habit formation in consumer expenditures can be modeled in terms of preferences or in terms of costs of adjustment that are reflected in a budget constraint.

Thus, if individuals are actually maximizing utility in the presence of at least partially unobservable work cost functions, but one estimates a structural model under the assumption 
that the data were generated by individuals maximizing utility subject only to the tax law generated budget constraint, then the data generating preferences would comprise both the underlying preferences and the work cost functions. As a result, estimation can proceed by specifying only the tax law generated budget constraint (and observable work costs, if any) and estimating the composite utility function. In effect, all of the known variables are used to construct the budget constraint, and the unknown preference and work cost parameters are all subsumed into estimated preferences.

However, one must be aware of the fact that, in doing so, work cost functions will indeed be subsumed into the estimated preferences. Further, since the shape of observable preferences are affected both by the shape of underlying preferences and by the shape of work cost functions, any characteristic of the observable preferences (such as nonconvexity or nonmonotonicity) could have resulted from the properties of any of the component functions. This aspect of the propositions presented above is similar in spirit to a result in Browning (1997), which shows that intertemporally nonadditive behavior could result either from nonadditivity in the budget constraint or nonadditivity in preferences.

Two main issues arise when specifying an estimation method that allows work costs to be subsumed into estimated preferences. First, one must be careful about the specification of heterogeneity used. To see this, suppose that there is heterogeneity in tastes for work, denoted by $v_{i}$, as well as heterogeneity in money work costs, denoted by $\omega_{i 1}$, and in time work costs, denoted by $\omega_{i 2}$. The individual's problem, then, is

$$
\begin{aligned}
& \max U\left(C, L, v_{i}\right) \\
\text { s.t. } C+F_{1}\left(h, \omega_{i 1}\right) \leq & f(W, Y, h, \theta) \\
h+F_{2}\left(h, \omega_{i 2}\right)+L & \leq \bar{H} .
\end{aligned}
$$

Using the technique in Proposition 1, this may be rewritten as

$$
\begin{aligned}
& \max U\left(O-F_{1}\left(h, \omega_{i 1}\right), \bar{H}-h-F_{2}\left(h, \omega_{i 2}\right), v_{i}\right) \\
\text { s.t. } O \leq & f(W, Y, h, \theta) .
\end{aligned}
$$

Depending on the assumptions one wishes to make about the joint distribution of $v_{i}, \omega_{i 1}$, and $\omega_{i 2}$, one may need to use a more complex stochastic specification than the two error specification that has been widely used in studies like Hausman (1981), Blomquist and Hansson-Brusewitz (1990), Triest (1990), and many others.

Second, the question occurs as to what effect the incorporation of the work costs into preferences will have on the shape of such preferences. We show in the next section that the resulting preferences may very likely be nonconvex. As such, one should be reticent about making the assumption that preferences are convex when implementing such an estimation method.

\subsection{Nonconvexity of Observable Preferences Due to Work Costs}

In this section, we demonstrate that when work costs are subsumed into observable preferences, those preferences will likely be nonconvex.

The following proposition demonstrates a necessary condition on the monetary and time costs of work functions for observable preferences to be nonconvex. Let outlays 
be $O=C+F_{1}(h)$, where $F_{1}(h)$ denotes the monetary costs of work. Let leisure be $L=\bar{H}-h-F_{2}(h)$, where $F_{2}(h)$ denotes the fixed time costs of work. Finally, let $U(C, L)$ represent underlying convex preferences over consumption and leisure, and $\widetilde{U}(O, h)$ represent observable preferences over outlays and leisure, where $\widetilde{U}(O, h)=U\left(O-F_{1}(h), \bar{H}-h-F_{2}(h)\right)$

Proposition 3 Strict concavity of either $F_{1}(h)$ or $F_{2}(h)$ over some range of $h$ is a necessary condition for observable preferences $\widetilde{U}(O, h)$ to be nonconvex.

Proof. Suppose not, that $F_{1}\left(\alpha h+(1-\alpha) h^{\prime}\right) \leq \alpha F_{1}(h)+(1-\alpha) F_{1}\left(h^{\prime}\right)$ and $F_{2}\left(\alpha h+(1-\alpha) h^{\prime}\right) \leq$ $\alpha F_{2}(h)+(1-\alpha) F_{2}\left(h^{\prime}\right)$ for all $h^{\prime} \neq h$ and $\alpha \in[0,1]$, but that $\widetilde{U}(O, h)$ is nonconvex. Then

$$
\begin{aligned}
& \widetilde{U}\left(\alpha O+(1-\alpha) O^{\prime}, \alpha h+(1-\alpha) h^{\prime}\right) \\
= & U\left(\begin{array}{c}
a O+(1-\alpha) O^{\prime}-F_{1}\left(\alpha h+(1-\alpha) h^{\prime}\right), \\
\bar{H}-\left(\alpha h+(1-\alpha) h^{\prime}\right)-F_{2}\left(\alpha h+(1-\alpha) h^{\prime}\right)
\end{array}\right) .
\end{aligned}
$$

Since $F_{1}\left(\alpha h+(1-\alpha) h^{\prime}\right) \leq \alpha F_{1}(h)+(1-\alpha) F_{1}\left(h^{\prime}\right)$ and $F_{2}\left(\alpha h+(1-\alpha) h^{\prime}\right) \leq \alpha F_{2}(h)+(1-$ a) $F_{2}\left(h^{\prime}\right)$, and $U(C, L)$ is monotonic in both arguments, we have

$$
\geq U\left(\begin{array}{c}
a\left[O-F_{1}(h)\right]+(1-\alpha)\left[O^{\prime}-F_{1}\left(h^{\prime}\right)\right], \\
\alpha\left[\bar{H}-h-F_{2}(h)\right]+(1-\alpha)\left[\bar{H}-h^{\prime}-F_{2}\left(h^{\prime}\right)\right]
\end{array}\right) .
$$

By the quasiconcavity of $U(C, L)$,

$$
\begin{aligned}
& \geq \min \left\{\begin{array}{c}
U\left(O-F_{1}(h), \bar{H}-h-F_{2}(h)\right), \\
U\left(O^{\prime}-F_{1}\left(h^{\prime}\right), \bar{H}-h^{\prime}-F_{2}\left(h^{\prime}\right)\right)
\end{array}\right\} \\
& =\min \left\{\widetilde{U}(O, h), \widetilde{U}\left(O^{\prime}, h^{\prime}\right)\right\} .
\end{aligned}
$$

Hence $\widetilde{U}(O, h)$ is quasiconcave, observed preferences are convex, and we have a contradiction.

Obviously, the sufficient condition for $\widetilde{U}(O, h)$ to be nonconvex is, for some $O \neq O^{\prime}$ and $h \neq h^{\prime}$,

$$
\begin{aligned}
& U\left(\begin{array}{c}
\alpha O+(1-\alpha) O^{\prime}-F_{1}\left(\alpha h+(1-\alpha) h^{\prime}\right), \\
\bar{H}-\left[\alpha h+(1-\alpha) h^{\prime}\right]-F_{2}\left(\alpha h+(1-\alpha) h^{\prime}\right)
\end{array}\right) \\
< & \min \left\{\begin{array}{c}
U\left(O-F_{1}(h), \bar{H}-h-F_{2}(h)\right), \\
U\left(O^{\prime}-F_{1}\left(h^{\prime}\right), \bar{H}-h^{\prime}-F_{2}\left(h^{\prime}\right)\right)
\end{array}\right\} .
\end{aligned}
$$

Essentially, this condition requires that $F_{1}(h)$ or $F_{2}(h)$ be sufficiently concave for observable preferences, $\widetilde{U}(O, h)$, to be nonconvex.

If one further makes the assumption that all functions are continuous and twice differentiable, it can be shown that the sufficient condition for observable preferences to be nonconvex becomes

$$
U_{1} \frac{\partial F_{1}}{\partial h^{2}}+U_{2} \frac{\partial F_{2}}{\partial h^{2}}+\frac{1}{U_{1}^{2}}\left(1+\frac{\partial F_{2}}{\partial h}\right)^{2}\left(-U_{1}^{2} U_{22}+2 U_{1} U_{2} U_{12}-U_{2}^{2} U_{11}\right) \leq 0,
$$


where $U_{i}$ denotes the partial derivative of $U$ with respect to its $i^{\text {th }}$ argument. To interpret this, under the assumption that underlying preferences are monotonic and convex, we know that $U_{1}$ and $U_{2}$, as well as the entire last term, are positive. Hence, the sufficient condition amounts to requiring that the second derivatives of either or both of the work cost functions be sufficiently negative so that the sum of the first two terms is larger in absolute value than the final term.

To assess the plausibility, then, that observable preferences are nonconvex, recall the discussion of the components of the costs of work in the previous section. These work costs vary in a complex manner with the number of hours worked, and may be concave in the number of hours, or even decrease over a range of hours. Thus, given the conditions above, it seems plausible that observable preferences over outlays and hours of work will exhibit nonconvexities. As a result, if one uses a method that relies on the assumption that preferences are convex while specifying the budget constraint as the budget constraint resulting from tax laws, then the model is likely misspecified.

In Heim and Meyer (2002), we examine the likely result of such a misspecification, in which the estimation method (such as that in Hall (1973), Hausman (1981), or MaCurdy et al. (1990)) relies on the assumption that preferences are convex, but that data generating preferences are actually nonconvex. We speculated that if one of these methods is used in the presence of such a misspecification, then the estimated parameters may exhibit wrongly signed compensated wage effects. Since compensated wage effects were either wrongly signed or constrained to be of the correct sign in a number of studies (See, for example, MaCurdy et al. (1990), Blomquist and Hannson-Brusewitz (1990), Colombino and Del Boca (1990), and Triest (1990)), it may be that not taking account of the complex form of costs of work in the estimation method led to the perplexing results in these studies.

As a result, if using the tax law generated budget constraint in a structural labor supply model, as often is necessary, one should be reticent about using a method that relies on the assumption that preferences are convex, and instead use a method that can estimate parameters consistent with both convex and nonconvex preferences. In Heim and Meyer (2002), we showed that all of the usual methods of estimating labor supply parameters, including local linearization, the Hausman method, and the MaCurdy method, cannot be modified to allow for the estimation of observably nonconvex preferences, and suggest methods that may be applied in this case.

\section{Difficulty of Separately Identifying Work Costs from Underlying Preferences}

Given the results above, if one does not explicitly account for costs of work in the budget constraint when estimating labor supply preferences, then the estimation method must attempt to estimate preferences that incorporate both the underlying preferences and the costs of work function.

It may be argued, then, that if work costs are not observed, the proper strategy is to jointly estimate utility and work cost functions. In this section, we analyze the wisdom of this approach. We first examine, if we make the assumption that underlying preferences 
satisfy certain properties, whether we can successfully test for the presence of work costs by examining whether observable preferences violate these properties. It turns out that only when work cost functions satisfy certain shape restrictions will such a test for the presence of work costs have power. We then show, however, that those shape restrictions do not deliver joint identification of all of the component functions of the observable preferences, even when additional shape restrictions are placed on the work cost functions. Hence, identification of the work cost functions will come from functional form assumptions. Thus, such a strategy may greatly complicate the estimation procedure, while only yielding tenuous estimates of preferences and work costs.

Formally, assume that underlying preferences are continuous, monotonically increasing, and convex. Let these preferences be represented by the utility function $U(C, L) \in \Theta_{1}$, which contains all continuous, monotonically increasing in both arguments, quasiconcave functions that represent unique preference orderings. Similarly, in the absence of time costs of work, these preferences could be represented by the utility function $U(C, \bar{H}-h)=\widehat{U}(C, h) \in \Theta_{2}$, which contains all continuous, quasiconcave functions that are monotonically increasing in the first and decreasing in the second argument. In the presence of monetary and time costs of work, $F_{1}(h)$ and $F_{2}(h)$ respectively, let observable preferences be represented by $\widetilde{U}(O, h)=$ $U\left(O-F_{1}(h), \bar{H}-h-F_{2}(h)\right)$. The following propositions demonstrate the conditions on $F_{1}(h)$ and $F_{2}(h)$ under which $\widetilde{U}(O, h) \notin \Theta_{2}$, and so, under the above assumptions on underlying preferences, a test for the presence of work costs by examining the properties of the observable preferences will have power.

Proposition 4 If $\frac{\frac{\partial F_{1}(h)}{\partial h}}{\left[1+\frac{\partial F_{2}(h)}{\partial h}\right]}<-\frac{\frac{\partial U}{\partial L}}{\frac{\partial U}{\partial C}}$ for some $C, L$, and $h$, where $L=\bar{H}-h-F_{2}(h)$, then a test for the presence of costs of work $F_{1}(h)$ and $F_{2}(h)$ will have power, due to the violation of monotonicity in $h$.

Proof. Suppose not. Then

$$
\begin{aligned}
& \frac{\partial \widetilde{U}(O, h)}{\partial h} \leq 0 \text { for all } O \text { and } h \\
& \Longrightarrow-\frac{\partial U}{\partial C} \frac{\partial F_{1}(h)}{\partial h}-\frac{\partial U}{\partial L}\left[1+\frac{\partial F_{2}(h)}{\partial h}\right] \leq 0 \\
& \Longrightarrow-\frac{\partial U}{\partial C} \frac{\partial F_{1}(h)}{\partial h} \leq \frac{\partial U}{\partial L}\left[1+\frac{\partial F_{2}(h)}{\partial h}\right] \\
& \Longrightarrow \frac{\frac{\partial F_{1}(h)}{\partial h}}{\left.1+\frac{\partial F_{2}(h)}{\partial h}\right]} \geq-\frac{\frac{\partial U}{\partial L}}{\frac{\partial U}{\partial C}} \Longrightarrow \Longleftarrow \text {. }
\end{aligned}
$$

Hence, under certain conditions on $F_{1}(h)$ and $F_{2}(h)$, a test for the presence of costs of work will have power, because observable preferences will not satisfy monotonicity. The following corollary establishes a necessary condition for a test for the presence of work costs to have power due to observable preferences not satisfying convexity.

Corollary 1 If $\frac{\frac{\partial F_{1}(h)}{\partial h}}{\left[1+\frac{\partial F_{2}(h)}{\partial h}\right]} \geq-\frac{\frac{\partial U}{\partial L}}{\frac{\partial U}{\partial C}}$ for all $C, L$, and $h$, where $L=\bar{H}-h-F_{2}(h)$, then strict concavity of either $F_{1}(h)$ or $F_{2}(h)$ over some range of $h$ is a necessary condition for a test for the presence of work costs to have power due to the violation of convexity of $\widetilde{U}(O, h)$. 
Proof. Suppose not. Applying Proposition 3 yields that $\widetilde{U}(O, h)$ is quasiconcave, and so a test for the presence of $F_{1}(h)$ and $F_{2}(h)$ will have no power.

Following the discussion in the previous section, the sufficient condition for a test for the presence of work costs to have power is for the condition in (16) to hold (or, if functions are twice differentiable, for the condition in (17) to hold), which again amounts to the costs of work functions being sufficiently concave (or for their second derivatives to be sufficiently negative).

Hence, under the assumption that the utility function, $U(C, L)$, is continuous, monotonic in both arguments, and quasiconcave, the costs of work functions, $F_{1}(h)$ and $F_{2}(h)$, must satisfy certain shape restrictions in order for the above described test for their presence to have power. We now show, however, that the assumption that preferences are continuous, monotonic and convex does not result in joint identification of the utility and costs of work functions, even if one places some additional shape restrictions on the costs of work function.

Suppose preferences are continuous, monotonically increasing, and convex. Let these preferences be represented by the utility function $U(C, L)$ which is an element of the set $\Theta$, which contains all continuous, monotonic, quasiconcave functions that represent unique preference orderings. In the presence of monetary and time costs of work, arbitrary function $F_{1}(h)$ and $F_{2}(h)$ which are element of the set of all functions $\Omega$, observable preferences are represented by $U\left(O-F_{1}(h), \bar{H}-h-F_{2}(h)\right)$.

Proposition 5 Given data on outlays, $O$, hours of work, $h$, and individuals' budget constraints, the utility function, $U(C, L)$, and costs of work functions, $F_{1}(h)$ and $F_{2}(h)$, are unidentified in $\Theta$ and $\Omega$, respectively.

Proof. Consider first a utility function $U(C, L)$ and work cost function $F_{1}(h)$ and $F_{1}(h)$, so that observable preferences are $U\left(O-F_{1}(h), \bar{H}-h-F_{2}(h)\right)$. Next, let $\phi_{1}, \phi_{2}, \phi_{3}$ and $\phi_{4}$ be scalars such that $0<\phi_{2}+\phi_{3}<1$ and $\phi_{2}+\phi_{4}>1$, and define $U^{\prime}(C, L)=$ $U\left(C+\phi_{1}, \phi_{2} L-\phi_{3}(\bar{H}-L)+\phi_{4} \bar{H}\right), F_{1}^{\prime}(h)=F_{1}(h)+\phi_{1}$, and $F_{2}^{\prime}(h)=\left(\frac{\phi_{2}+\phi_{4}-1}{\phi_{2}+\phi_{3}}\right) \bar{H}+$ $\left(\frac{1}{\phi_{2}+\phi_{3}}\right) F_{2}(h)+\left(\frac{1-\phi_{2}+\phi_{3}}{\phi_{2}+\phi_{3}}\right) h$. We need to verify that that observable preferences are equivalent, that $U^{\prime}(C, L) \in \Theta$, and that $F_{1}^{\prime}(h), F_{2}^{\prime}(h) \in \Omega$. Clearly, since $\Omega$ is the set of all functions, the last condition is satisfied. Next, note that observable preferences in the two cases are equivalent, since

$$
\begin{aligned}
& U^{\prime}\left(O-F_{1}^{\prime}(h), \bar{H}-h-F_{2}^{\prime}(h)\right) \\
= & U^{\prime}\left(\bar{H}-h-\left[\left(\frac{\phi_{2}+\phi_{4}-1}{\phi_{2}+\phi_{3}}\right) \bar{H}+\left(\frac{1}{\phi_{2}+\phi_{3}}\right) F_{2}(h)+\left(\frac{1-\phi_{2}+\phi_{3}}{\phi_{2}+\phi_{3}}\right)\right] h\right) \\
= & U\left(O-F_{1}(h), \bar{H}-h-F_{2}(h)\right) .
\end{aligned}
$$

Further, the two utility functions represent different preferences, since $U^{\prime}$ is not a strictly increasing transformation of $U$. So, it remains to show that $U^{\prime}(C, L)$ is monotonically increasing in both arguments and quasiconcave.

First, $\frac{\partial U^{\prime}}{\partial C}=U_{1} \geq 0$, where $U_{i}$ denotes the derivative of $U$ with respect to the $i^{\text {th }}$ argument. 
Second, $\frac{\partial U^{\prime}}{\partial L}=\left[\phi_{2}+\phi_{3}\right] U_{2}$, Since $\phi_{2}+\phi_{3}>0$, then $\frac{\partial U^{\prime}}{\partial L}>0$, and hence monotonicity is established.

Finally, take $C^{\prime} \neq C, L^{\prime} \neq L$ and note that for all $\alpha \in[0,1]$,

$$
\begin{aligned}
& U^{\prime}\left(\alpha C+(1-\alpha) C^{\prime}, \alpha L+(1-\alpha) L^{\prime}\right) \\
= & U\left(\begin{array}{c}
{\left[\alpha C+(1-\alpha) C^{\prime}\right]+\phi_{1},} \\
\phi_{2}\left[\alpha L+(1-\alpha) L^{\prime}\right]-\phi_{3}\left(\bar{H}-\left[\alpha L+(1-\alpha) L^{\prime}\right]\right)+\phi_{4} \bar{H}
\end{array}\right) \\
= & U\left(\begin{array}{c}
\alpha\left[C+\phi_{1}\right]+(1-\alpha)\left[C^{\prime}+\phi_{1}\right] \\
\left.\alpha\left[\phi_{2} L-\phi_{3}(\bar{H}-L)+\phi_{4} \bar{H}\right]+(1-\alpha)\left[\phi_{2} L^{\prime}-\phi_{3}\left(\bar{H}-L^{\prime}\right)+\phi_{4} \bar{H}\right]\right) .
\end{array}\right.
\end{aligned}
$$

Since $U(C, L)$ is quasiconcave,

$$
\begin{aligned}
& \geq \min \left\{\begin{array}{c}
U\left(C+\phi_{1}, \phi_{2} L-\phi_{3}(\bar{H}-L)+\phi_{4} \bar{H}\right), \\
U\left(C^{\prime}+\phi_{1}, \phi_{2} L^{\prime}-\phi_{3}\left(\bar{H}-L^{\prime}\right)+\phi_{4} \bar{H}\right)
\end{array}\right\} \\
& =\min \left\{U^{\prime}(C, L), U^{\prime}\left(C^{\prime}, L^{\prime}\right)\right\} .
\end{aligned}
$$

Hence, $U^{\prime}(C, L)$ is quasiconcave. Thus, $\exists U^{\prime}(C, L) \in \Theta$ and $F_{1}^{\prime}(h), F_{2}^{\prime}(h) \in \Omega$ such that observable preferences are the same, and hence $U(C, L), F_{1}(h)$, and $F_{2}(h)$ are unidentified in $\Theta$ and $\Omega$, respectively.

Hence, although we can test for the presence of costs of work if we make some assumptions about the shape of the utility function, those assumptions alone do not deliver joint identification of the utility and costs of work functions.

Further, note that assuming $F_{1}(h)$ and $F_{2}(h)$ are increasing and/or concave also does not yield identification. To see this, note that if $F_{1}(h)$ and $F_{2}(h)$ satisfy these shape restrictions, $F_{1}^{\prime}(h)$ and $F_{2}^{\prime}(h)$ also satisfy these, and the rest of the proof follows. Other shape restrictions might yield joint identification, but the imposition of such restrictions would be ad hoc, since given the above discussion of the components of the costs of work, few plausible restrictions can be placed a priori on the shape of this function. In practice, then, if work costs are unobservable, any separate identification of preferences and work costs will likely come from functional form assumptions.

It would seem, then, that since preferences and work costs are not separately identified in estimation, that if work costs are unobservable, the usual policy analyses could either not be performed, or would be so sensitive to specification as to render them meaningless. However, in the next section, we show that one can estimate the composite utility function without making any effort to separate out preferences from work costs, and still perform many policy relevant calculations.

\section{$5 \quad$ Irrelevance of Composition of Estimated Preferences to Some Policy and Welfare Analyses}

Given the previous propositions, the question arises whether not being able to separately identify preferences and costs of work functions will have an effect on certain policy analyses. 
Clearly, if costs of work are not separately estimated, some calculations cannot be performed, such as examining the labor supply effects of implementing a tax credit for child care costs.

In this section, however, we show that the inability to reliably estimate the work cost functions separately from preferences does not preclude us from making some of the most common policy relevant calculations. Namely, we show that the results of the most common policy and welfare calculations are invariant to whether the shape of estimated preferences arises solely from the shape of underlying preferences, or some amalgamation of underlying preferences and work costs. Further, these results hold whether or not estimated preferences are nonconvex.

The key to these propositions is that the proposed policy change must not affect the shape of the work cost functions. As such, work costs must not be treated differently in the tax code than consumption (or leisure time). ${ }^{9}$

Suppose, first, we are interested in the effect of a change in the tax law generated budget constraint, from $f\left(W, Y, h, \theta_{1}\right)$ to $f\left(W, Y, h, \theta_{2}\right)$, on an individual's labor supply. Using the notation of Section 3, consider an estimated (possibly composite) utility function $\widetilde{U}(O, h)$, which may consist of work costs subsumed into observable preferences, or may consist solely of underlying preferences. Let $h_{1}$ be the hours of work that maximize this function on the budget constraint $f\left(W, Y, h, \theta_{1}\right)$, and $h_{2}$ be the hours that maximize this function on the budget constraint $f\left(W, Y, h, \theta_{2}\right)$. Note that, given Proposition 1 , the hours that maximize underlying utility on the two budget constraints would be $h_{1}$ and $h_{2}$, respectively, regardless of whether $\widetilde{U}(O, h)$ consists solely of preferences, or consists of preferences augmented by work costs. Hence, the estimate of the labor supply effect of the change in the tax generated budget constraint is the same in either case. As a result, given estimates of $\widetilde{U}(O, h)$, we can proceed to examine the effect of such a policy change as if the estimated preferences consisted solely of underlying preferences.

In the rest of this section, we show that even if work costs are not separately identified, deadweight loss calculations may also be performed, again with the caveat that work costs must not be treated differently than consumption (or leisure time) in the tax code. Namely, the following subsections demonstrate that the calculation of the deadweight loss of an income tax that does not affect work costs is invariant to whether preferences have monetary or time work costs contained within them, even in the presence of progressive or other nonproportional taxation. As such, we can proceed to make the deadweight loss calculation as if estimated preferences consisted solely of underlying preferences.

\subsection{Proportional Tax Case}

In this section, we demonstrate that the calculation of deadweight loss due to a proportional tax on labor income is invariant to whether the shape of the estimated indifference curve arises out of the individual's underlying preferences, or due to the presence of some costs of work.

First, consider a case in which observable possibly nonconvex preferences over consumption and leisure are represented by the utility function $\bar{U}(C, L)$, which in the absence of costs

\footnotetext{
${ }^{9}$ One should also note that we are assuming there are no general equilibrium effects of the tax policy change, or the tax code, that change the magnitude of work costs.
} 
of work could also be represented as $\overline{\bar{U}}(C, h)=\bar{U}(C, \bar{H}-h)$. Second, consider another case in which the underlying preferences over consumption and leisure are represented by $\widehat{U}(C, L)$. However, suppose that due to monetary costs of work, $F_{1}(h)$, and time costs of work $F_{2}(h)$, we observe preferences $\widehat{\widehat{U}}(O, h)$, where $\widehat{\widehat{U}}(O, h)=\widehat{U}\left(O-F_{1}(h), \bar{H}-F_{2}(h)-h\right)$. Finally, let $\overline{\bar{U}}(a, b)=\widehat{\widehat{U}}(a, b)$, so that both sets of observable indifference curves over $O$ (which equals $C$ in the absence of time costs) and $h$ have the same form, and hence are observationally equivalent if we cannot observe the costs of work.

The following proposition demonstrates that, under a proportional tax, the deadweight loss of the tax is invariant to whether the observed shape of the indifference curve is due to underlying preferences, or due to work costs being incorporated into underlying preferences to yield the observable preferences.

Proposition 6 The deadweight loss from imposing a proportional tax, $t$, on an individual with possibly nonconvex preferences $\bar{U}(C, L)$, which may be represented in the absence of costs of work as $\overline{\bar{U}}(C, h)=\bar{U}(C, \bar{H}-h)$, equals the deadweight loss from imposing a proportional tax, $t$, on an individual with underlying preferences $\widehat{U}(C, L)$ and possibly nonconvex observable preferences $\widehat{\widehat{U}}(O, h)=\widehat{U}\left(O-F_{1}(h), \bar{H}-F_{2}(h)-h\right)$, where $\overline{\bar{U}}(a, b)=\widehat{\widehat{U}}(a, b)$.

Proof. See Appendix B.

For a sketch of the proof, consider Figures 1 and 2, which illustrate these propositions in the presence of monetary work costs. Figure 1 demonstrates the calculation of deadweight loss when the underlying preferences are nonconvex. In this case, the leisure the individual consumes is $L_{0}^{*}$, which corresponds to working hours $h_{0}^{*}$, and the unearned income required to be able to afford this point is $e\left(W(1-t), u_{0}\right)=C_{0}^{*}-(1-t) W h_{0}^{*}$. If the tax were not in place, the individual could have reached the same level of utility with unearned income $e\left(W, u_{0}\right)=\widetilde{C}_{0}-W \widetilde{h}_{0}$. The amount of income tax the government collects is $R=t W h_{0}^{*}$, and hence the deadweight loss of the income tax is

$$
\begin{aligned}
D W L_{0} & =e\left(W(1-t), u_{0}\right)-e\left(W, u_{0}\right)-R \\
& =\left[C_{0}^{*}-(1-t) W h_{0}^{*}\right]-\left[\widetilde{C}-W \widetilde{h}_{0}\right]-t W h_{0}^{*} .
\end{aligned}
$$

In Figure 2, the indifference curve is only observably nonconvex because of the presence of the costs of work. However, the observable indifference curve, $\widehat{\widehat{U}}(O, h)$, is exactly the same shape as in the previous figure. Thus, the individual consumes the same amount of leisure, $L_{1}^{*}=L_{0}^{*}$, and works the same number of hours $h_{1}^{*}=h_{0}^{*}$. Consumption is lower in this figure, but the total amount of outlays in this figure, $O_{1}^{*}=C_{1}^{*}+F_{1}\left(h_{1}^{*}\right)$, equals the amount of consumption in Figure $1, C_{0}^{*}$.

So, to calculate the deadweight loss in this case, we first note that at the optimal consumption and leisure bundle in the presence of the tax, unearned income must be $e\left(W(1-t), u_{0}\right)=C_{1}^{*}+F_{1}\left(h_{1}^{*}\right)-(1-t) W h_{1}^{*}$. If the tax were not in place, the individual could have reached the same level of utility with unearned income $e\left(W, u_{0}\right)=\widetilde{C}_{1}+F_{1}\left(\widetilde{h}_{1}\right)-W \widetilde{h}_{1}$. The amount of revenue that the government collects is $R=t W h_{1}^{*}$, and so the deadweight loss of the proportional tax in this figure is 


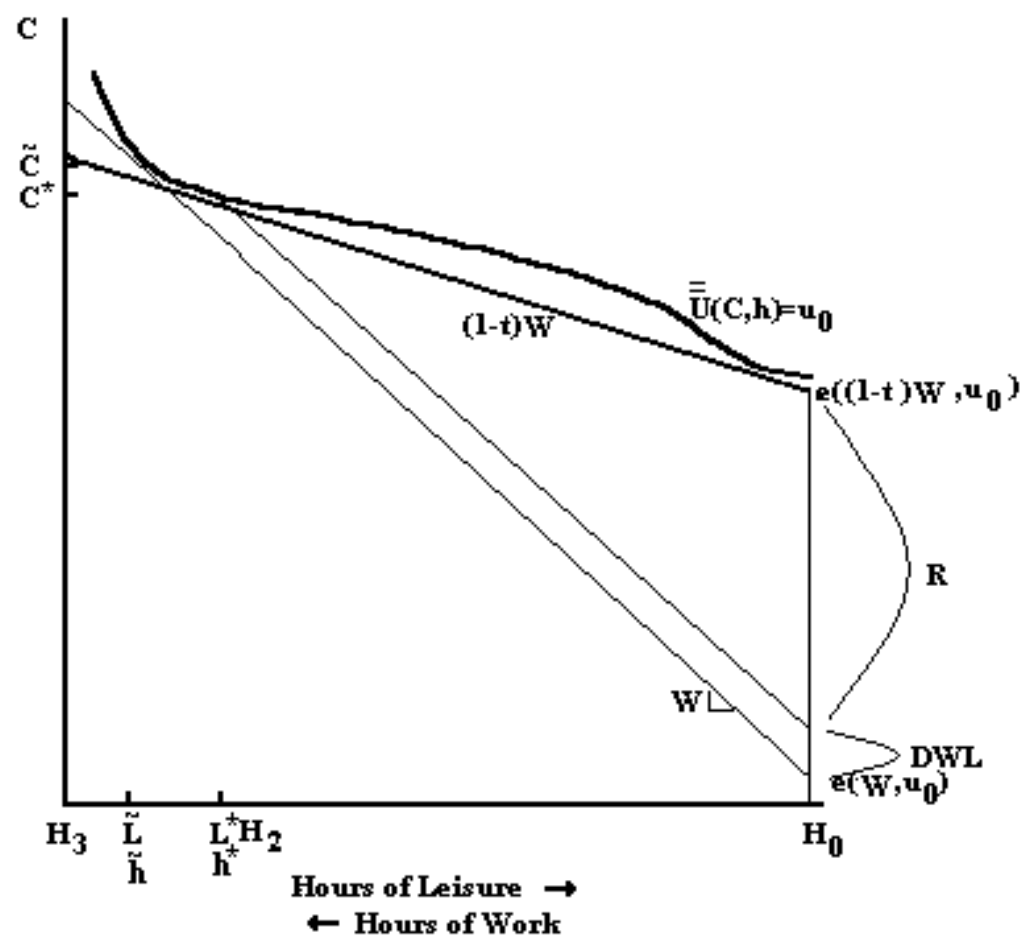

Figure 1: Graphical Demonstration of Proposition 6 - Nonconvex Inherent Preferences

$$
\begin{aligned}
D W L_{1}= & e\left(W(1-t), u_{0}\right)-e\left(W, u_{0}\right)-R \\
= & {\left[C_{1}^{*}+F_{1}\left(h_{1}^{*}\right)-(1-t) W h_{1}^{*}\right] } \\
& \left.\quad-\left[\widetilde{C}_{1}+F_{1}\left(\widetilde{h}_{1}\right)-W \widetilde{h}_{1}\right)\right]-t W h_{1}^{*} \\
= & {\left[O_{1}^{*}-(1-t) W h_{1}^{*}\right]-\left[\widetilde{O}_{1}-W \widetilde{h}_{1}\right]-t W h_{1}^{*} . }
\end{aligned}
$$

Finally, since $O_{1}^{*}, \widetilde{O}_{1}, h_{1}^{*}$, and $\widetilde{h}_{1}$ in Figure 2 are the same amounts as $C_{0}^{*}, \widetilde{C}_{0}, h_{0}^{*}$, and $\widetilde{h}_{0}$, respectively, in Figure 1, the two deadweight losses are the same.

Thus, if we calculate the deadweight loss explicitly accounting for the fact that observable preferences have work costs embedded within them, we get the same quantity as when we calculate deadweight loss using a utility function whose indifference curves have the same shape. As such, given estimates of preferences that may or may not subsume work costs, we can proceed calculating the deadweight loss as if the estimated preferences consist solely of underlying preferences.

\subsection{Nonproportional Tax Case}

The result in the previous subsection also applies to the nonproportional tax case, in that the deadweight loss calculation is invariant to the source of the shape of indifference curves. 


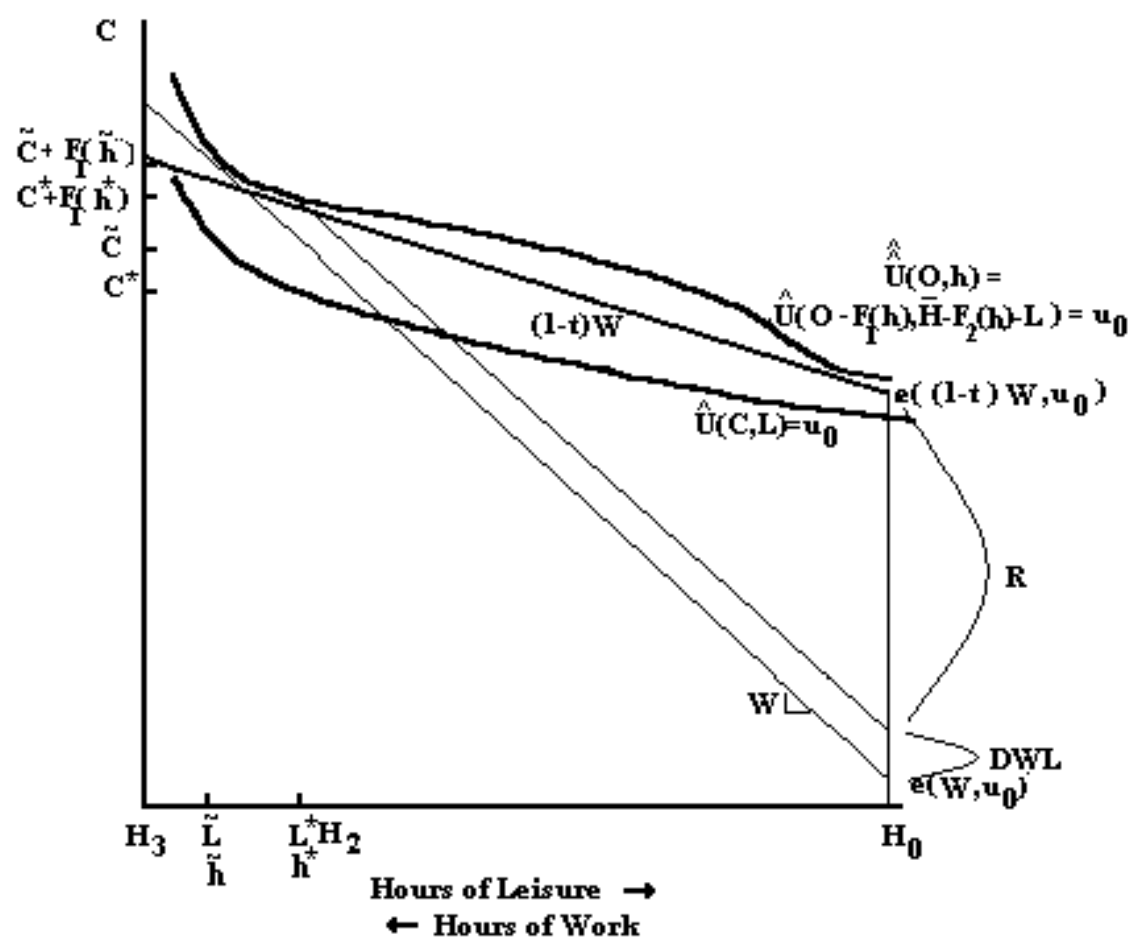

Figure 2: Graphical Demonstration of Proposition 6 - Nonconvex Observable Preferences

Following the notation in the previous subsection, consider a case in which observable possibly nonconvex preferences over consumption and leisure are represented by the utility function $\bar{U}(C, L)$, which may also be represented by $\overline{\bar{U}}(C, h)$. Second, consider another case in which, the underlying preferences over consumption and leisure are represented by $\widehat{U}(C, L)$. However, suppose that due to monetary costs of work, $F_{1}(h)$, and time costs of work, $F_{2}(h)$, we observe preferences $\widehat{\widehat{U}}(O, h)$, where $\widehat{\widehat{U}}(O, h)=\widehat{U}\left(O-F_{1}(h), \bar{H}-F_{2}(h)-h\right)$. Further, let $\widehat{U}(a, b)=\overline{\bar{U}}(a, b)$, so that both sets of indifference curves over $O$ and $h$ have the same form, and hence are observationally equivalent if we cannot observe the costs of work.

Finally, suppose income is taxed with a nonproportional tax schedule defined by $\left\{t_{j}, H_{j}\right\}_{j=1}^{J}$, in which the marginal tax rate is $t_{j}$ on hours of work between $H_{j-1}$ and $H_{j}$. (See Figure $3)$.

Proposition 7 The deadweight loss from imposing the nonproportional tax schedule $\left\{t_{j}, H_{j}\right\}_{j=1}^{J}$ on an agent with possibly nonconvex preferences $\bar{U}(C, L)$, which may be represented in the absence of costs of work as $\overline{\bar{U}}(C, h)=\bar{U}(C, \bar{H}-h)$ equals the deadweight loss from imposing the nonproportional tax schedule $\left\{t_{j}, H_{j}\right\}_{j=1}^{J}$ on an agent with underlying preferences $\widehat{U}(C, L)$ and possibly nonconvex observable preferences $\widehat{\widehat{U}}(O, h)=\widehat{U}\left(O-F_{1}(h), \bar{H}-F_{2}(h)-h\right)$, where $\overline{\bar{U}}(a, b)=\widehat{\widehat{U}}(a, b)$.

Proof. See Appendix B. 


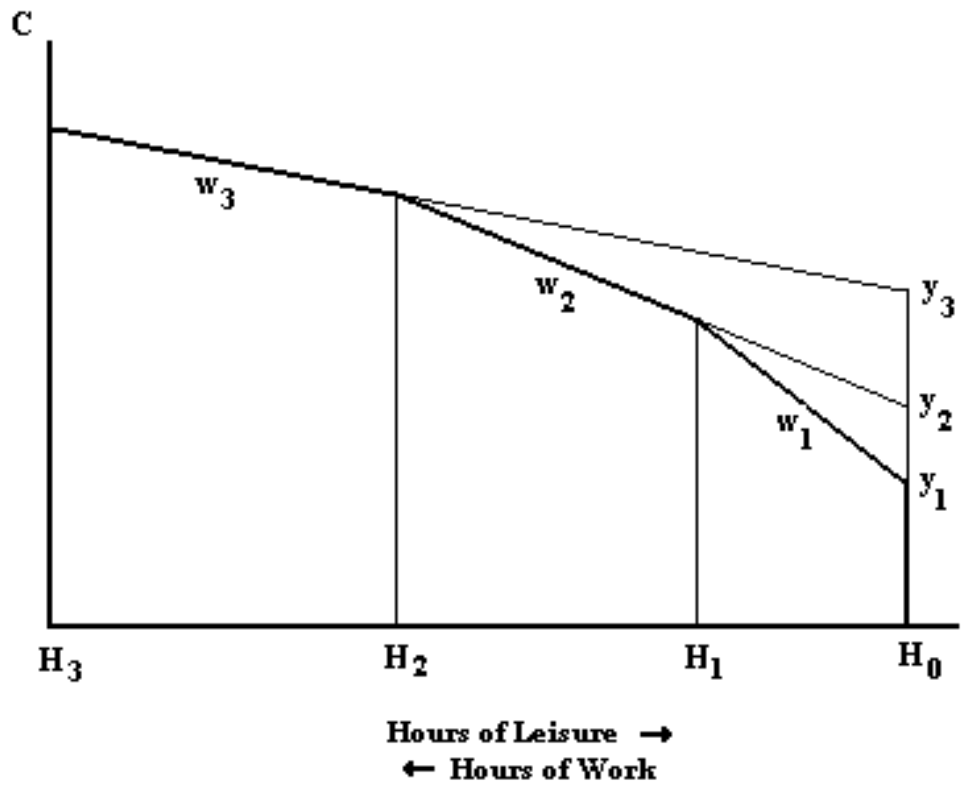

Figure 3: Nonlinear Budget Constraint 


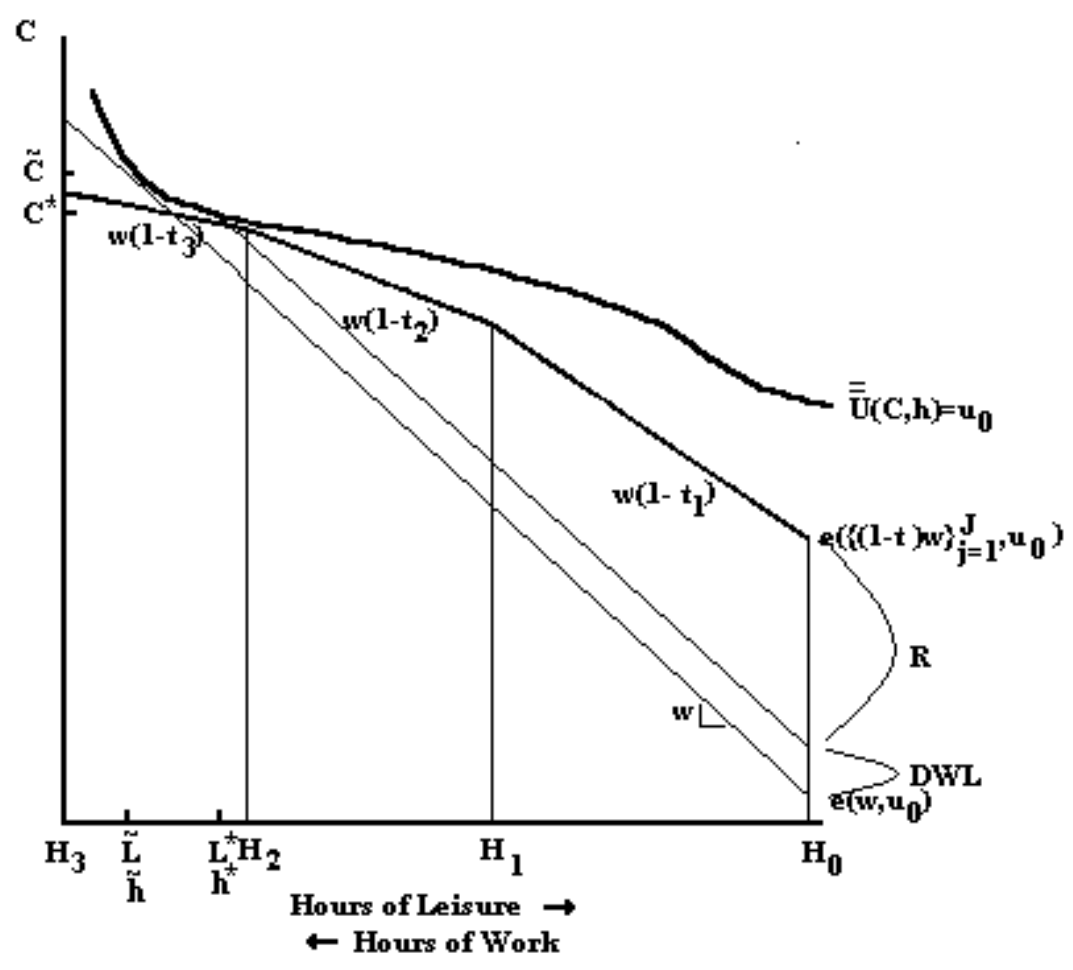

Figure 4: Graphical Demonstration of Proposition 7 - Nonconvex Inherent Preferences

For a graphical example of this proposition, see Figures 4 and 5. The argument is very similar to that in the previous proposition.

Thus, even in the presence of nonproportional taxation, given estimates of observable preferences, we can proceed to calculate deadweight loss as if the observable preferences are comprised only of underlying preferences, because the deadweight loss is the same whether or not the observable preferences subsume work costs within.

The intuition behind the previous two results is straightforward. As was noted above, the tax distortion on the consumption-leisure choice is unaffected by the source of the shape of the indifference curve, so long as the items that influence that shape of the indifference curves (the monetary and time costs of work) are not treated differently in tax law.

Further, it should be noted that these propositions also hold if some work costs are observable and accounted for in the budget constraint, and other work costs are unobservable and subsumed into estimated preferences. In addition, these propositions not only hold for linear and piecewise linear budget constraints, but also for an arbitrarily shaped continuous budget constraint. Finally, a similar proposition applies to goods or activities other than labor supply, when the consumption of such a good or activity involves the expenditure of time and/or money. Proofs of these claims are presented in Appendix C.

Thus, the question becomes whether the costs of work are actually treated differently by tax law. Clearly, time costs of work are not affected by tax law. Since we believe time costs outside of the workplace are the main work costs, our results should largely apply. Money costs of work are more likely to be deductible, particularly child care costs. In such 


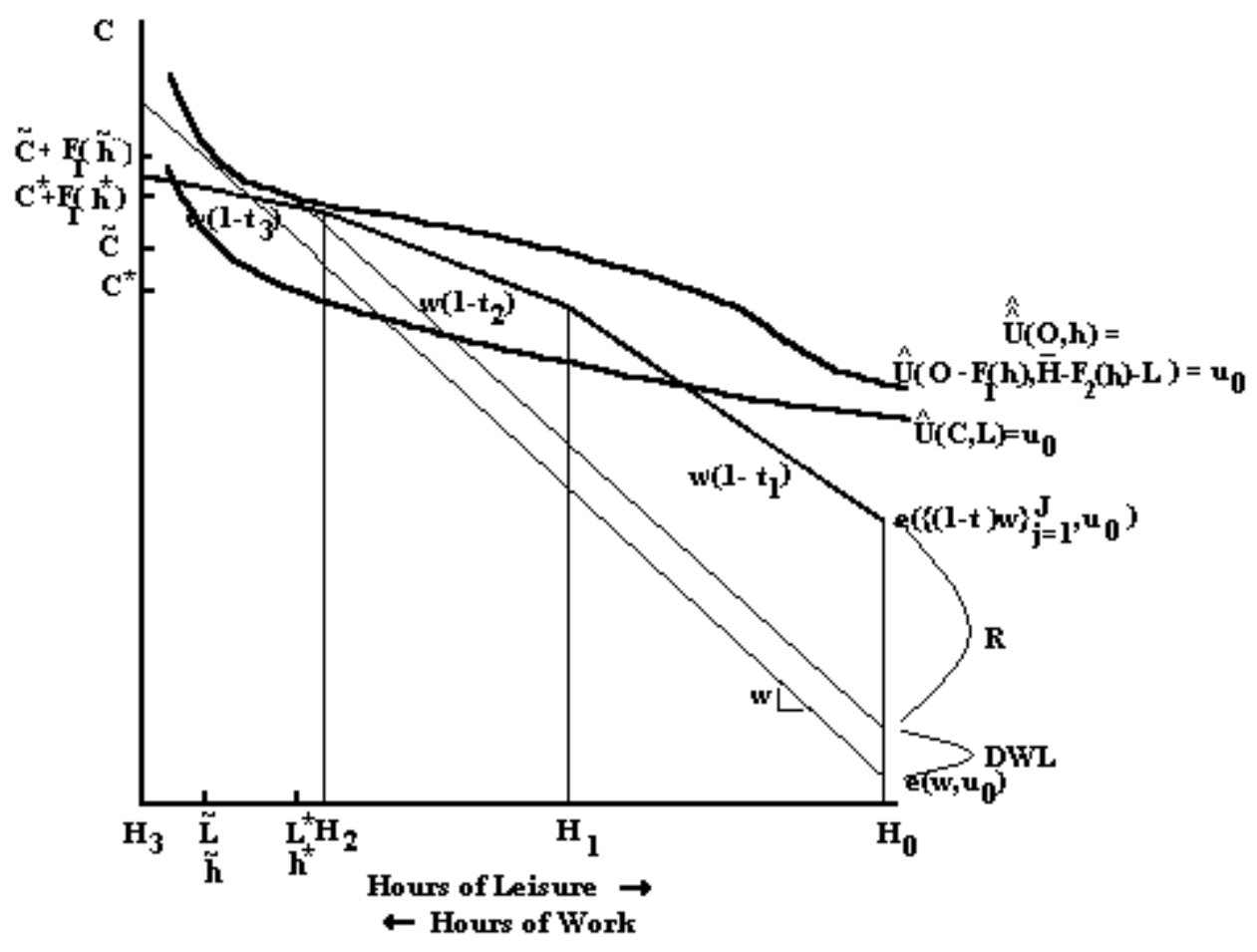

Figure 5: Graphical Demonstration of Proposition 7 - Nonconvex Observable Preferences

situations, our DWL propositions are less applicable. However, child care costs are often not deductible in the U.S. Furthermore, in the U.S. and elsewhere the regular costs of travel to or from work are not deductible. Overall, given the preponderance of time costs of work, most work costs are not likely to be differentially treated under tax systems, and the above propositions should be largely applicable.

\section{Conclusion}

In this paper, we critique the manner in which work costs have been incorporated into structural labor supply models. We then show that, even if one does not think a priori that underlying preferences are nonconvex, if one ignores the costs of work in the formulation of a structural labor supply estimation approach, then the estimation method must contend with the fact that work cost functions will be incorporated into observable preferences. We then show that the incorporation of the work cost functions into observable preferences will likely yield preferences that are nonconvex.

Since a realistic explicit incorporation of the costs of work is often infeasible in structural labor supply estimation, this result implies that one should be wary of making the assumption that preferences are convex when estimating labor supply parameters. The result further provides a rationale for the contention in Heim and Meyer (2002) that a possible reason for the perplexing findings in the literature that estimated labor supply functions violated 
basic economic assumptions is that previous estimation methods were being used on data generated by individuals with nonconvex (or observably nonconvex preferences), which is contrary to the assumed data generating process.

We then show that once work costs are allowed to be subsumed into observable preferences, joint identification of the work costs and utility functions is not possible if we only make plausible assumptions about the shapes of the utility and work cost functions. Although the inability to jointly identify the utility and costs of work functions, absent functional form assumptions, means that estimates of these preferences cannot be used to simulate the effects of some policies, we show they can be used to simulate the labor supply effects of changes in tax policy if work costs remain unchanged, or to estimate the deadweight loss of the income tax.

Whether estimated preferences are actually nonconvex, of course, is an empirical issue. This paper, however, provides a theoretical rationale as to why researchers should use estimation methods in which estimated parameters may represent nonconvex preferences, and provides guidance about the policy analyses that may safely be performed with such parameters.

\section{Appendix A - Generalization of Behavioral Model}

In the setup of the consumers problem in Section 3, the assumption was implicitly made that monetary and time work costs were exogenously given and denoted by $F_{1}(h)$ and $F_{2}(h)$, respectively. In this section, we show that the results in this section may, with slight changes, be adapted to a more general setting in which an individual's work cost functions are not exogenously given, but rather are the result of the individual optimizing over all of their possible choices of transportation to work, child care, and so on. Once this change is made, generalizations of the other propositions in the paper follow.

So, suppose that individuals have various modes by which their transportation to work, child care, work clothing, and so on could be satisfied. Number these modes $m=1,2, \ldots, M$. Corresponding to each of these modes are the money cost of working $h$ hours, $F_{1}^{m}(h)$, and the time cost of working $h$ hours, $F_{2}^{m}(h)$, and some other characteristics $X_{m}$. For example, considering transportation, the individual could drive, ride a bike, take a train, take a bus, carpool with others, and so on, and corresponding to each of these options are the time and money involved in transportation to work so that the individual could work $h$ hours, and some additional characteristics, such as comfort, convenience of schedules, etc.

\subsection{No preference over mode characteristics}

Suppose initially that the individual only cares about the time and money associated with each mode. In this case, the individual's utility maximization problem is

$$
\begin{aligned}
& \max _{C, L, h, m} U(C, L) \\
\text { s.t.C }+F_{1}^{m}(h) \leq & f(W, Y, h, \theta) \\
L+h+F_{2}^{m}(h) \leq & \bar{H} .
\end{aligned}
$$


So, the individual chooses the time and budget constraints subject to which they maximize their utility. The optimal choice will consist of a mode $m$, and the optimal $h, L$, and $C$ that maximize utility subject to the budget and time constraints corresponding to mode $m$. We can rewrite this problem as

$$
\begin{aligned}
& \max _{O, h, m} U\left(O-F_{1}^{m}(h), \bar{H}-h+F_{2}^{m}(h)\right) \\
\text { s.t. } O \leq & f(W, Y, h, \theta) .
\end{aligned}
$$

Writing it this way, the individual chooses the function they maximize subject to the same constraint, and the optimal choice will consist of a mode $m$ and the optimal $h$ and $O$ that maximize the objective function corresponding to mode $m$ subject to the constraint.

This can be further rewritten in two parts, the first of which is

$$
m(O, h)=\arg \max _{m}\left\{U\left(O-F_{1}^{m}(h), \bar{H}-h+F_{2}^{m}(h)\right) \mid O, h\right\} .
$$

Here, $m(O, h)$ is a policy function which denotes the optimal choice of mode given that the individual will spend outlays in the amount of $O$ and will work $h$ hours. This function, given discrete mode choices, will generally be a step function. Given this function, the individual solves the problem

$$
\begin{aligned}
& \max _{O, h} U\left(O-F_{1}^{m(O, h)}(h), \bar{H}-h+F_{2}^{m(O, h)}(h)\right) \\
\text { s.t.O } \leq & f(W, Y, h, \theta) .
\end{aligned}
$$

If we let $F_{1}(O, h)=F_{1}^{m(O, h)}(h)$ and $F_{2}(O, h)=F_{2}^{m(O, h)}(h)$, this can finally be rewritten as

$$
\begin{array}{rl} 
& \max _{O, h} U\left(O-F_{1}(O, h), \bar{H}-h+F_{2}(O, h)\right) \\
\text { s.t. } O & f(W, Y, h, \theta),
\end{array}
$$

which is the same as (4), with the exception that the work cost functions are now functions of outlays as well as hours. Letting

$$
\widetilde{U}(O, h)=U\left(O-F_{1}(O, h), \bar{H}-h+F_{2}(O, h)\right)
$$

yields a result analogous to that in Section 3.

Generalizations of the preference shape propositions in Section 4 to this setting are straightforward. Further, since the observable preferences in this case are still not a function of tax parameters, generalizations of the policy analysis and deadweight loss propositions in Section 5 will also still hold.

\subsection{Preference over mode characteristics}

Suppose now that individuals have preferences over the characteristics of each mode, so that the individual's problem is

$$
\begin{aligned}
& \max _{C, L, h, m} U\left(C, L, X_{m}\right) \\
\text { s.t. } C+F_{1}^{m}(h) \leq & f(W, Y, h, \theta) \\
L+h+F_{2}^{m}(h) \leq & \bar{H}
\end{aligned}
$$


Again, rewrite this problem as

$$
\begin{aligned}
& \max _{O, h, m} U\left(O-F_{1}^{m}(h), \bar{H}-h+F_{2}^{m}(h), X_{m}\right) \\
\text { s.t.O } \leq & f(W, Y, h, \theta) .
\end{aligned}
$$

This can again be considered in a two stage frame work, the first of which is

$$
m(O, h)=\arg \max _{m}\left\{U\left(O-F_{1}^{m}(h), \bar{H}-h+F_{2}^{m}(h), X_{m}\right) \mid O, h\right\} .
$$

Again, $m(O, h)$ is a policy function, which denotes the optimal choice of mode given the characteristics of each mode, and given that the individual spends outlays, $O$, and works hours, $h$. Given this function, the individual solves the problem

$$
\begin{aligned}
& \max _{O, h} U\left(O-F_{1}^{m(O, h)}(h), \bar{H}-h+F_{2}^{m(O, h)}(h), X_{m(O, h)}\right) \\
\text { s.t.O } \leq & f(W, Y, h, \theta) .
\end{aligned}
$$

If we let $F_{1}(O, h)=F_{1}^{m(O, h)}(h)$ and $F_{2}(O, h)=F_{2}^{m(O, h)}(h)$, this can finally be rewritten as

$$
\begin{aligned}
& \max _{O, h} U\left(O-F_{1}(O, h), \bar{H}-h+F_{2}(O, h), X_{m(O, h)}\right) \\
\text { s.t.O } \leq & f(W, Y, h, \theta) .
\end{aligned}
$$

Letting $\widetilde{U}(O, h)=U\left(O-F_{1}(O, h), \bar{H}-h+F_{2}(O, h), X_{m(O, h)}\right)$ yields a result analogous to that in Section 3.

Again, generalizations of the preference shape propositions in Section 4 to this setting are straightforward. Also, the observable preferences are once again not a function of tax parameters, and so generalizations of the policy analysis and deadweight loss propositions in Section 5 will once again still hold.

\section{Appendix B - Proofs of Deadweight Loss Proposi- tions}

In this appendix, we present proofs of the deadweight loss propositions in Section 5.

Proposition 6. The deadweight loss from imposing a proportional tax, $t$, on an individual with possibly nonconvex preferences $\bar{U}(C, L)$, which may be represented in the absence of costs of work as $\overline{\bar{U}}(C, h)=\bar{U}(C, \bar{H}-h)$ equals the deadweight loss from imposing a proportional tax, $t$, on an individual with underlying preferences $\widehat{U}(C, L)$ and possibly nonconvex observable preferences $\widehat{\widehat{U}}(O, h)=\widehat{U}\left(O-F_{1}(h), \bar{H}-F_{2}(h)-h\right)$, where $\overline{\bar{U}}(a, b)=\widehat{\widehat{U}}(a, b)$. Proof. Let

$$
\left(C_{0}^{*}, L_{0}^{*}\right)=\arg \max _{C, L}\{\bar{U}(C, L): C \leq(1-t) W h+Y, h=\bar{H}-L\},
$$


where $W$ is the gross wage, $Y$ is nonlabor income, and the price of consumption is normalized to 1. (See Figure 1) This may be written in an equivalent way as

$$
\left(C_{0}^{*}, h_{0}^{*}\right)=\arg \max _{C, h}\{\overline{\bar{U}}(C, h): C \leq(1-t) W h+Y\} .
$$

Let

$$
u_{0}=\bar{U}\left(C_{0}^{*}, L_{0}^{*}\right)=\overline{\bar{U}}\left(C_{0}^{*}, h_{0}^{*}\right) .
$$

Using the duality between the utility maximization problem and the expenditure minimization problem, we have the value of the expenditure function evaluated at $u_{0}$,

$$
e\left((1-t) W, u_{0}\right)=C_{0}^{*}-W(1-t) h_{0}^{*}
$$

Now, let

$$
\left(\widetilde{C}_{0}, \widetilde{L}_{0}\right)=\arg \min _{C, L}\left\{C-W h: \bar{U}(C, L) \geq u_{0}, h=\bar{H}-L\right\},
$$

which has an equivalent formulation as

$$
\left(\widetilde{C}_{0}, \widetilde{h}_{0}\right)=\arg \min _{C, h}\left\{C-W h: \overline{\bar{U}}(C, h) \geq u_{0}\right\} .
$$

Clearly, by the definition of the expenditure function,

$$
e\left(W, u_{0}\right)=\widetilde{C}_{0}-W \widetilde{h}_{0} .
$$

Finally, let the taxes collected by the government be characterized by $R_{0}$, where

$$
R_{0}=t W h_{0}^{*}
$$

By the definition of deadweight loss,

$$
D W L_{0}=e\left((1-t) W, u_{0}\right)-e\left(W, u_{0}\right)-R_{0} .
$$

Substituting (44), (47), and (48) into (49) yields

$$
D W L_{0}=\left[C_{0}^{*}-(1-t) W h_{0}^{*}\right]-\left[\widetilde{C}_{0}-W \widetilde{h}_{0}\right]-t W h_{0}^{*}
$$

Now, let

$$
\left(C_{1}^{*}, L_{1}^{*}, h_{1}^{*}\right)=\arg \max _{C, L, h}\left\{\begin{array}{c}
\widehat{U}(C, L): C \leq(1-t) W h+Y-F_{1}(h), \\
L=\bar{H}-F_{2}(h)-h
\end{array}\right\} .
$$

For reference, see Figure 2. Letting $u_{1}=\widehat{U}\left(C_{1}^{*}, L_{1}^{*}\right)$, by the definition of the expenditure function, we have

$$
e\left((1-t) W, u_{1}\right)=C_{1}^{*}-W(1-t) h_{1}^{*}+F_{1}\left(h_{1}^{*}\right) .
$$

To evaluate this quantity, note that we can use $O=C+F_{1}(h) \Longrightarrow C=O-F_{1}(h)$ to write (51) in an equivalent form as

$$
\left(O_{1}^{*}, h_{1}^{*}\right)=\arg \max _{O, h}\left\{\widehat{U}\left(O-F_{1}(h), \bar{H}-F_{2}(h)-h\right): O \leq(1-t) W h+Y\right\}
$$


which can be further rewritten as

$$
\left(O_{1}^{*}, h_{1}^{*}\right)=\arg \max _{O, h}\{\widehat{\widehat{U}}(O, h): O \leq(1-t) W h+Y\} .
$$

Since $\widehat{\widehat{U}}(a, b)=\overline{\bar{U}}(a, b)$, it is clear that $O_{1}^{*}=C_{0}^{*}$, and $h_{1}^{*}=h_{0}^{*}$. Using these equalities, along with the property that $C_{1}^{*}=O_{1}^{*}-F_{1}\left(h_{1}^{*}\right)$, yields that $(52)$ is equal to

$$
e\left((1-t) W, u_{1}\right)=C_{0}^{*}-W(1-t) h_{0}^{*}
$$

Now, let

$$
\left(\widetilde{C}_{1}, \widetilde{L}_{1}, \widetilde{h}_{1}\right)=\arg \min _{C, L, h}\left\{C-W h+F_{1}(h): \widehat{U}(C, L) \geq u_{1}, L=\bar{H}-F_{2}(h)-h\right\} .
$$

By the definition of the expenditure function, we have

$$
e\left(W, u_{1}\right)=\widetilde{C}_{1}+F_{1}\left(\widetilde{h}_{1}\right)-W \widetilde{h}_{1}
$$

Note, however, that since

$$
\begin{aligned}
u_{1} & =\widehat{U}\left(C_{1}^{*}, L_{1}^{*}\right) \\
& =\widehat{U}\left(O_{1}^{*}-F_{1}\left(h_{1}^{*}\right), H-h_{1}^{*}-F_{2}\left(h_{1}^{*}\right)\right) \\
& =\widehat{\widehat{U}}\left(O_{1}^{*}, h_{1}^{*}\right) \\
& =\overline{\bar{U}}\left(C_{0}^{*}, h_{0}^{*}\right)=u_{0},
\end{aligned}
$$

and using $C=O-F_{1}(h),(56)$ may be rewritten

$$
\left(\widetilde{O}_{1}, \widetilde{h}_{1}\right)=\arg \min _{O, h}\left\{O-W h: \widehat{U}\left(O-F_{1}(h), \bar{H}-F_{2}(h)-h\right) \geq u_{0}\right\},
$$

which, by the definition of $\widehat{\widehat{U}}(O, h)$, becomes

$$
\left(\widetilde{O}_{1}, \widetilde{h}_{1}\right)=\arg \min _{O, h}\left\{O-W h: \widehat{\widehat{U}}(O, h) \geq u_{0}\right\} .
$$

Since $\overline{\bar{U}}(a, b)=\widehat{\widehat{U}}(a, b)$, it is clear that $\widetilde{O}_{1}=\widetilde{C}_{0}$ and $\widetilde{h}_{1}=\widetilde{h}_{0} . \quad$ Using $\widetilde{C}_{1}=\widetilde{O}_{1}-F_{1}\left(\widetilde{h}_{1}\right)$, these equalities yield that (57) is equal to

$$
e\left(W, u_{1}\right)=\widetilde{C}_{0}-W \widetilde{h}_{0} .
$$

Finally, the tax revenue is

$$
R_{1}=t W h_{1}^{*},
$$

which, since $h_{1}^{*}=h_{0}^{*}$ as noted above, implies

$$
R_{1}=t W h_{0}^{*}
$$


In this case,

$$
D W L_{1}=e\left((1-t) W, u_{1}\right)-e\left(W, u_{1}\right)-R_{1} .
$$

Substituting (55), (61), and (63) into (64), and comparing with (50) yields the result.

Proposition 7. The deadweight loss from imposing the nonproportional tax schedule $\left\{t_{j}, H_{j}\right\}_{j=1}^{J}$ on an agent with possibly nonconvex preferences $\bar{U}(C, L)$, which may be represented in the absence of costs of work as $\overline{\bar{U}}(C, h)=\bar{U}(C, \bar{H}-h)$ equals the deadweight loss from imposing the progressive tax schedule $\left\{t_{j}, H_{j}\right\}_{j=1}^{J}$ on an agent with underlying preferences $\widehat{U}(C, L)$ and possibly nonconvex observable preferences $\widehat{\widehat{U}}(O, h)=\widehat{U}\left(O-F_{1}(h), \bar{H}-\right.$ $\left.F_{2}(h)-h\right)$, where $\overline{\bar{U}}(a, b)=\widehat{\widehat{U}}(a, b)$.

Proof. Consider a choice of consumption and hours of work,

$$
\left(C_{0}^{*}, L_{0}^{*}\right)=\arg \max _{C, L}\left\{C \leq Y+\sum_{j=1}^{J}\left[\begin{array}{c}
\bar{U}(C, L): \\
\left(1-t_{j}\right) W\left(h-H_{j-1}\right) \\
+\sum_{k=1}^{j-1}\left(1-t_{k}\right) W\left(H_{k}-H_{k-1}\right) \\
\times 1\left(H_{j-1} \leq h<H_{j}\right) \\
h=\bar{H}-L
\end{array}\right],\right\}
$$

where $W$ is the gross wage, $Y$ is nonlabor income, $\bar{H}$ is the time endowment, and the price of consumption is normalized to 1 . For reference, see Figure 4 . This may be written in an equivalent way as

$$
\left(C_{0}^{*}, h_{0}^{*}\right)=\arg \max _{C, h}\left\{C \leq Y+\sum_{j=1}^{J}\left[\left[\begin{array}{c}
\overline{\bar{U}}(C, h): \\
\left(1-t_{j}\right) W\left(h-H_{j-1}\right) \\
+\sum_{k=1}^{j-1}\left(1-t_{k}\right) W\left(H_{k}-H_{k-1}\right) \\
\times 1\left(H_{j-1} \leq h<H_{j}\right)
\end{array}\right]\right] .\right.
$$

Let

$$
u_{0}=\bar{U}\left(C_{0}^{*}, L_{0}^{*}\right)=\overline{\bar{U}}\left(C_{0}^{*}, h_{0}^{*}\right) .
$$

Using the duality between the utility maximization problem and the expenditure minimization problem, we have the value of the expenditure function evaluated at $u_{0}$,

$$
e\left(\left\{\left(1-t_{j}\right) W\right\}_{j=1}^{J}, u_{0}\right)=C_{0}^{*}-\sum_{j=1}^{J}\left[\left[\begin{array}{c}
\left(1-t_{j}\right) W\left(h_{0}^{*}-H_{j-1}\right) \\
+\sum_{k=1}^{j-1}\left(1-t_{k}\right) W\left(H_{k}-H_{k-1}\right) \\
\times 1\left(H_{j-1} \leq h_{0}^{*}<H_{j}\right)
\end{array}\right] .\right.
$$

Now, let

$$
\left(\widetilde{C}_{0}, \widetilde{L}_{0}\right)=\arg \min _{C, L}\left\{C-W h: \bar{U}(C, L) \geq u_{0}, h=\bar{H}-L\right\},
$$

which also has an equivalent formulation as

$$
\left(\widetilde{C}_{0}, \widetilde{h}_{0}\right)=\arg \min _{C, h}\left\{C-W h: \overline{\bar{U}}(C, h) \geq u_{0}\right\} .
$$

Clearly, by the definition of the expenditure function,

$$
e\left(W, u_{0}\right)=\widetilde{C}_{0}-W \widetilde{h}_{0} .
$$


Finally, let the taxes collected by the government be characterized by $R_{0}$, where

$$
R_{0}=\sum_{j=1}^{J}\left[\begin{array}{c}
t_{j} W\left(h_{0}^{*}-H_{j-1}\right) \\
+\sum_{k=1}^{j-1} t_{k} W\left(H_{k}-H_{k-1}\right)
\end{array}\right] 1\left(H_{j-1} \leq h_{0}^{*}<H_{j}\right) .
$$

By the definition of deadweight loss,

$$
D W L_{0}=e\left(\left\{\left(1-t_{j}\right) W\right\}_{j=1}^{J}, u_{0}\right)-e\left(W, u_{0}\right)-R_{0} .
$$

Substitution of (68), (71) and (72) into (73) yields

$$
\begin{aligned}
D W L_{0}= & C_{0}^{*}-\sum_{j=1}^{J}\left[\left[\begin{array}{c}
\left(1-t_{j}\right) W\left(h_{0}^{*}-H_{j-1}\right) \\
+\sum_{k=1}^{j-1}\left(1-t_{k}\right) W\left(H_{k}-H_{k-1}\right) \\
\times 1\left(H_{j-1} \leq h_{0}^{*}<H_{j}\right)
\end{array}\right]\right] \\
& \left.-\left[\widetilde{C}_{0}-W \widetilde{h}_{0}\right]-\sum_{j=1}^{J}\left[\begin{array}{c}
t_{j} W\left(h_{0}^{*}-H_{j-1}\right) \\
+\sum_{k=1}^{j-1} t_{k} W\left(H_{k}-H_{k-1}\right) \\
\times 1\left(H_{j-1} \leq h_{0}^{*}<H_{j}\right)
\end{array}\right]\right] .
\end{aligned}
$$

Now, let

$$
\left(C_{1}^{*}, L_{1}^{*}, h_{1}^{*}\right)=\arg \max _{C, L, h}\left\{+\sum_{j=1}^{J}\left[\left[\begin{array}{c}
\widehat{U}(C, L): C \leq Y \\
\left(1-t_{j}\right) W\left(h-H_{j-1}\right) \\
+\sum_{k=1}^{j-1}\left(1-t_{k}\right) W\left(H_{k}-H_{k-1}\right) \\
\times 1\left(H_{j-1} \leq h<H_{j}\right)-F_{1}(h) \\
L=\bar{H}-F_{2}(h)-h
\end{array}\right],\right\} .\right.
$$

For reference, see Figure 5. Letting $u_{1}=\widehat{U}\left(C_{1}^{*}, L_{1}^{*}\right)$, by definition of the expenditure function, we have

$$
\begin{gathered}
e\left(\left\{\left(1-t_{j}\right) W\right\}_{j=1}^{J}, u_{1}\right)= \\
C_{1}^{*}+F_{1}\left(h_{1}^{*}\right) \\
-\sum_{j=1}^{J}\left[\begin{array}{c}
\left(1-t_{j}\right) W\left(h_{1}^{*}-H_{j-1}\right) \\
+\sum_{k=1}^{j-1}\left(1-t_{k}\right) W\left(H_{k}-H_{k-1}\right) \\
\times 1\left(H_{j-1} \leq h_{1}^{*}<H_{j}\right)
\end{array}\right]
\end{gathered}
$$

To evaluate this quantity, note that we can use $O=C+F_{1}(h) \Longrightarrow C=O-F_{1}(h)$ to write (75) in an equivalent form as

$$
\left(O_{1}^{*}, h_{1}^{*}\right)=\arg \max _{O, h}\left\{\begin{array}{c}
\widehat{U}\left(O-F_{1}(h), \bar{H}-F_{2}(h)-h\right): \\
\left.O \leq Y+\sum_{j=1}^{J}\left[\begin{array}{c}
\left(1-t_{j}\right) W\left(h-H_{j-1}\right) \\
+\sum_{k=1}^{j-1}\left(1-t_{k}\right) W\left(H_{k}-H_{k-1}\right) \\
\times 1\left(H_{j-1} \leq h<H_{j}\right)
\end{array}\right]\right]
\end{array}\right.
$$

which can be further rewritten as

$$
\left(O_{1}^{*}, h_{1}^{*}\right)=\arg \max _{O, h}\left\{\begin{array}{c}
\widehat{\widehat{U}}(O, h): \\
\left(1-t_{j}\right) W\left(h-H_{j-1}\right) \\
\left.O \leq Y+\sum_{j=1}^{J}\left[\begin{array}{c}
j-1 \\
+\sum_{k=1}\left(1-t_{k}\right) W\left(H_{k}-H_{k-1}\right) \\
\times 1\left(H_{j-1} \geq h>H_{j}\right)
\end{array}\right]\right] .
\end{array}\right.
$$


Since $\widehat{\widehat{U}}(a, b)=\overline{\bar{U}}(a, b)$, it is clear that $O_{1}^{*}=C_{0}^{*}$ and $h_{1}^{*}=h_{0}^{*}$. Using these equalities, along with the property that $C_{1}^{*}=O_{1}^{*}-F_{1}\left(h_{1}^{*}\right)$, yields that $(76)$ is equal to

$$
e\left(\left\{\left(1-t_{j}\right) W\right\}_{j=1}^{J}, u_{1}\right)=C_{0}^{*}-\sum_{j=1}^{J}\left[\left[\begin{array}{c}
\left(1-t_{j}\right) W\left(h_{0}^{*}-H_{j-1}\right) \\
+\sum_{k=1}^{j-1}\left(1-t_{k}\right) W\left(H_{k}-H_{k-1}\right) \\
\times 1\left(H_{j-1} \leq h_{0}^{*}<H_{j}\right)
\end{array}\right] .\right.
$$

Now, let

$$
\left(\widetilde{C}_{1}, \widetilde{L}_{1}, \widetilde{h}_{1}\right)=\arg \min _{C, L, h}\left\{C-W h+F_{1}(h): \widehat{U}(C, L) \geq u_{1}, L=\bar{H}-F_{2}(h)-h\right\} .
$$

Then, by the definition of the expenditure function, we have

$$
e\left(W, u_{1}\right)=\widetilde{C}_{1}+F_{1}\left(\widetilde{h}_{1}\right)-W \widetilde{h}_{1} .
$$

Note, however, that since

$$
\begin{aligned}
u_{1} & =\widehat{U}\left(C_{1}^{*}, L_{1}^{*}\right) \\
& =\widehat{U}\left(O_{1}^{*}-F_{1}\left(h_{1}^{*}\right), \bar{H}-F_{2}\left(h_{1}^{*}\right)-h_{1}^{*}\right) \\
& =\widehat{\widehat{U}}\left(O_{1}^{*}, h_{1}^{*}\right) \\
& =\overline{\bar{U}}\left(C_{0}^{*}, h_{0}^{*}\right)=u_{0},
\end{aligned}
$$

and using $C=O-F_{1}(h),(80)$ may be rewritten

$$
\left(\widetilde{O}_{1}, \widetilde{h}_{1}\right)=\arg \min _{O, h}\left\{O-W h: \widehat{U}\left(O-F_{1}(h), \bar{H}-F_{2}(h)-h\right) \geq u_{0}\right\},
$$

which, by the definition of $\widehat{\widehat{U}}(O, h)$, becomes

$$
\left(\widetilde{O}_{1}, \widetilde{h}_{1}\right)=\arg \min _{O, h}\left\{O-W h: \widehat{\widehat{U}}(O, h) \geq u_{0}\right\} .
$$

Since $\overline{\bar{U}}(a, b)=\widehat{\widehat{U}}(a, b)$, it is clear that $\widetilde{O}_{1}=\widetilde{C}_{0}$, and $\widetilde{h}_{1}=\widetilde{h}_{0}$. Using $\widetilde{C}_{1}=\widetilde{O}_{1}-F_{1}\left(\widetilde{h}_{1}\right)$, these equalities imply that (81) is equal to

$$
e\left(W, u_{1}\right)=\widetilde{C}_{0}-W \widetilde{h}_{0} .
$$

Finally, the tax revenue is

$$
R_{1}=\sum_{j=1}^{J}\left[\begin{array}{c}
t_{j} W\left(h_{1}^{*}-H_{j-1}\right) \\
+\sum_{k=1}^{j-1} t_{k} W\left(H_{k}-H_{k-1}\right)
\end{array}\right] 1\left(H_{j-1} \leq h_{1}^{*}<H_{j}\right),
$$

which, since $h_{1}^{*}=h_{0}^{*}$ as noted above, implies

$$
R_{1}=\sum_{j=1}^{J}\left[\begin{array}{c}
t_{j} W\left(h_{0}^{*}-H_{j-1}\right) \\
+\sum_{k=1}^{j-1} t_{k} W\left(H_{k}-H_{k-1}\right)
\end{array}\right] 1\left(H_{j-1} \leq h_{0}^{*}<H_{j}\right) .
$$

In this case,

$$
D W L_{1}=e\left(\left\{\left(1-t_{j}\right) W\right\}_{j=1}^{J}, u_{1}\right)-e\left(W, u_{1}\right)-R_{1} .
$$

Substitution of (79), (85), and (63) into (88), and comparing with (74) yields the result. 


\section{Appendix C - Generalizations of Deadweight Loss Propositions}

In this appendix, we present proofs of some generalizations of the main deadweight loss equivalence propositions.

\subsection{Arbitrary Budget Constraint}

The following proposition demonstrates the deadweight loss equivalence for an arbitrary budget constraint.

Proposition 8 The deadweight loss from imposing the nonproportional tax schedule $f(W, Y, h, \theta)$ on an agent with possibly nonconvex preferences $\bar{U}(C, L)$, which may be represented in the absence of costs of work as $\overline{\bar{U}}(C, h)=\bar{U}(C, \bar{H}-h)$, equals the deadweight loss from imposing this same tax schedule on an agent with underlying preferences $\widehat{U}(C, L)$ and unobservable monetary and time work costs, $F_{1}(h)$ and $F_{2}(h)$, yielding possibly nonconvex observable preferences $\widehat{\widehat{U}}(O, h)=\widehat{U}\left(O-F_{1}(h), \bar{H}-F_{2}(h)-h\right)$, where $\overline{\bar{U}}(a, b)=\widehat{\widehat{U}}(a, b)$.

Proof. Consider a choice of consumption and hours of work,

$$
\left(C_{0}^{*}, L_{0}^{*}\right)=\arg \max _{C, L}\{\bar{U}(C, L): C \leq f(W, Y, h, \theta), h=\bar{H}-L\}
$$

where $W$ is the gross wage, $Y$ is nonlabor income, $\theta$ are tax parameters, $f(W, Y, h, \theta)$ is

the after tax income from working $h$ hours, $\bar{H}$ is the time endowment, and the price of consumption is normalized to 1 . This may be written in an equivalent way as

$$
\left(C_{0}^{*}, h_{0}^{*}\right)=\arg \max _{C, h}\{\overline{\bar{U}}(C, h): C \leq f(W, Y, h, \theta)\}
$$

Let

$$
u_{0}=\bar{U}\left(C_{0}^{*}, L_{0}^{*}\right)=\overline{\bar{U}}\left(C_{0}^{*}, h_{0}^{*}\right) .
$$

Using the duality between the utility maximization problem and the expenditure minimization problem, we have the value of the expenditure function evaluated at $u_{0}$,

$$
e\left(W, \theta, u_{0}\right)=Y
$$

Now, let

$$
\left(\widetilde{C}_{0}, \widetilde{L}_{0}\right)=\arg \min _{C, L}\left\{C-W h: \bar{U}(C, L) \geq u_{0}, h=\bar{H}-L\right\},
$$

which also has an equivalent formulation as

$$
\left(\widetilde{C}_{0}, \widetilde{h}_{0}\right)=\arg \min _{C, h}\left\{C-W h: \overline{\bar{U}}(C, h) \geq u_{0}\right\} .
$$

Clearly, by the definition of the expenditure function,

$$
e\left(W, u_{0}\right)=\widetilde{C}_{0}-W \widetilde{h}_{0} .
$$


Finally, let the taxes collected by the government be characterized by $R_{0}$, where

$$
R_{0}=Y+W h_{0}^{*}-C_{0}^{*} .
$$

By the definition of deadweight loss,

$$
D W L_{0}=e\left(W, \theta, u_{0}\right)-e\left(W, u_{0}\right)-R_{0} .
$$

Substitution of (92), (95) and (96) into (97) yields

$$
D W L_{0}=Y-\left[\widetilde{C}_{0}+F_{1}^{o}\left(\widetilde{h}_{0}\right)-W \widetilde{h}_{0}\right]-\left[Y+W h_{0}^{*}-C_{0}^{*}-F_{1}^{o}\left(h_{0}^{*}\right)\right] .
$$

Now, let

$$
\left(C_{1}^{*}, L_{1}^{*}, h_{1}^{*}\right)=\arg \max _{C, L, h}\left\{\begin{array}{c}
\widehat{U}(C, L): \\
C \leq f(W, Y, h, \theta)-F_{1}(h), \\
L=\bar{H}-F_{2}(h)-h
\end{array}\right\} .
$$

To evaluate these quantities, note that we can substitute in the time constraint, and use $O=C+F_{1}(h) \Longrightarrow C=O-F_{1}(h)$ to write (99) in an equivalent form as

$$
\left(O_{1}^{*}, h_{1}^{*}\right)=\arg \max _{O, h}\left\{\begin{array}{c}
\widehat{U}\left(O-F_{1}(h), \bar{H}-F_{2}(h)-h\right): \\
O \leq f(W, Y, h, \theta)
\end{array}\right\},
$$

which can be further rewritten as

$$
\left(O_{1}^{*}, h_{1}^{*}\right)=\arg \max _{O, h}\{\widehat{\widehat{U}}(O, h): O \leq f(W, Y, h, \theta)\} .
$$

Since $\widehat{\widehat{U}}(a, b)=\overline{\bar{U}}(a, b)$, comparing (101) to $(90)$, it is clear that $O_{1}^{*}=C_{0}^{*}$ and $h_{1}^{*}=h_{0}^{*}$. Letting $u_{1}=U\left(C_{1}^{*}, L_{1}^{*}\right)$, again using the duality between the utility maximization problem and the expenditure minimization problem, we have the vale of the expenditure function evaluated at $u_{1}$,

$$
e\left(W, \theta, u_{1}\right)=Y
$$

Now, let

$$
\left(\widetilde{C}_{1}, \widetilde{L}_{1}, \widetilde{h}_{1}\right)=\arg \min _{C, L, h}\left\{C+F_{1}(h)-W h: \widehat{U}(C, L) \geq u_{1}, L=\bar{H}-F_{2}(h)-h\right\} .
$$

Then, by the definition of the expenditure function, we have

$$
e\left(W, u_{1}\right)=\widetilde{C}_{1}+F_{1}\left(\widetilde{h}_{1}\right)-W \widetilde{h}_{1} .
$$

Note, however, that since

$$
\begin{aligned}
u_{1} & =\widehat{U}\left(C_{1}^{*}, L_{1}^{*}\right) \\
& =\widehat{U}\left(O_{1}^{*}-F_{1}\left(h_{1}^{*}\right), \bar{H}-F_{2}\left(h_{1}^{*}\right)-h_{1}^{*}\right) \\
& =\widehat{\widehat{U}}\left(O_{1}^{*}, h_{1}^{*}\right) \\
& =\overline{\bar{U}}\left(C_{0}^{*}, h_{0}^{*}\right)=u_{0},
\end{aligned}
$$


and using $C=O-F_{1}(h),(103)$ may be rewritten

$$
\left(\widetilde{O}_{1}, \widetilde{h}_{1}\right)=\arg \min _{O, h}\left\{O-W h: \widehat{U}\left(O-F_{1}(h), \bar{H}-F_{2}(h)-h\right) \geq u_{0}\right\},
$$

which, by the definition of $\widehat{\widehat{U}}(O, h)$, becomes

$$
\left(\widetilde{O}_{1}, \widetilde{h}_{1}\right)=\arg \min _{O, h}\left\{O-W h: \widehat{\widehat{U}}(O, h) \geq u_{0}\right\} .
$$

Since $\overline{\bar{U}}(a, b)=\widehat{\widehat{U}}(a, b)$, comparing $(107)$ to $(94)$, it is clear that $\widetilde{O}_{1}=\widetilde{C}_{0}$, and $\widetilde{h}_{1}=\widetilde{h}_{0}$. Using $\widetilde{C}_{1}=\widetilde{O}_{1}-F_{1}\left(\widetilde{h}_{1}\right)$, these equalities imply that (104) is equal to

$$
e\left(W, u_{1}\right)=\widetilde{C}_{0}-W \widetilde{h}_{0}
$$

Finally, the tax revenue is

$$
\begin{aligned}
R_{1} & =Y+W h_{1}^{*}-C_{1}^{*}-F_{1}\left(h_{1}^{*}\right) \\
& =Y+W h_{1}^{*}-O_{1}^{*},
\end{aligned}
$$

which, since $O_{1}^{*}=C_{0}^{*}$ and $h_{1}^{*}=h_{0}^{*}$ as noted above, implies

$$
R_{1}=Y+W h_{0}^{*}-C_{0}^{*}
$$

In this case,

$$
D W L_{1}=e\left(W, \theta, u_{1}\right)-e\left(W, u_{1}\right)-R_{1}
$$

Substitution of (102), (108), and (110) into (111), and comparing with (98) yields the result.

\subsection{Work Costs Partially Observable}

The following proposition demonstrates the deadweight loss equivalence when some time and money work costs are observable, and other time and money work costs are unobservable.

Proposition 9 In the presence of observable monetary work costs, $F_{1}^{o}(h)$, and observable time work costs, $F_{2}^{o}(h)$, the deadweight loss from imposing the nonproportional tax schedule $f(W, Y, h, \theta)$ on an agent with possibly nonconvex preferences $\bar{U}(C, L)$, which may be represented in the absence of costs of work as $\overline{\bar{U}}(C, h)=\bar{U}(C, \bar{H}-h)$, equals the deadweight loss from imposing this same tax schedule on an agent with underlying preferences $\widehat{U}(C, L)$ and unobservable monetary and time work costs, $F_{1}^{u}(h)$ and $F_{2}^{u}(h)$, yielding possibly nonconvex observable preferences $\widehat{\widehat{U}}(O, h)=\widehat{U}\left(O-F_{1}^{u}(h), \bar{H}-F_{2}^{u}(h)-h\right)$, where $\overline{\bar{U}}(a, b)=\widehat{\widehat{U}}(a, b)$.

Proof. Consider a choice of consumption and hours of work,

$$
\left(C_{0}^{*}, L_{0}^{*}\right)=\arg \max _{C, L}\left\{\bar{U}(C, L): C \leq f(W, Y, h, \theta)-F_{1}^{o}(h), h+F_{2}^{o}(h)=\bar{H}-L\right\}
$$


where $W$ is the gross wage, $Y$ is nonlabor income, $\theta$ are tax parameters, $f(W, Y, h, \theta)$ is the after tax income from working $h$ hours, $\bar{H}$ is the time endowment, and the price of consumption is normalized to 1 . This may be written in an equivalent way as

$$
\left(C_{0}^{*}, h_{0}^{*}\right)=\arg \max _{C, h}\left\{\overline{\bar{U}}\left(C, h+F_{2}^{o}(h)\right): C \leq f(W, Y, h, \theta)-F_{1}^{o}(h)\right\} .
$$

Let

$$
u_{0}=\bar{U}\left(C_{0}^{*}, L_{0}^{*}\right)=\overline{\bar{U}}\left(C_{0}^{*}, h_{0}^{*}+F_{2}^{o}\left(h_{0}^{*}\right)\right) .
$$

Using the duality between the utility maximization problem and the expenditure minimization problem, we have the value of the expenditure function evaluated at $u_{0}$,

$$
e\left(W, \theta, u_{0}\right)=Y
$$

Now, let

$$
\left(\widetilde{C}_{0}, \widetilde{L}_{0}\right)=\arg \min _{C, L}\left\{C+F_{1}^{o}(h)-W h: \bar{U}(C, L) \geq u_{0}, h+F_{2}^{o}(h)=\bar{H}-L\right\},
$$

which also has an equivalent formulation as

$$
\left(\widetilde{C}_{0}, \widetilde{h}_{0}\right)=\arg \min _{C, h}\left\{C+F_{1}^{o}(h)-W h: \overline{\bar{U}}\left(C, h+F_{2}^{o}(h)\right) \geq u_{0}\right\} .
$$

Clearly, by the definition of the expenditure function,

$$
e\left(W, u_{0}\right)=\widetilde{C}_{0}+F_{1}^{o}\left(\widetilde{h}_{0}\right)-W \widetilde{h}_{0}
$$

Finally, let the taxes collected by the government be characterized by $R_{0}$, where

$$
R_{0}=Y+W h_{0}^{*}-C_{0}^{*}-F_{1}^{o}\left(h_{0}^{*}\right) .
$$

By the definition of deadweight loss,

$$
D W L_{0}=e\left(W, \theta, u_{0}\right)-e\left(W, u_{0}\right)-R_{0}
$$

Substitution of (115), (118) and (119) into (120) yields

$$
D W L_{0}=Y-\left[\widetilde{C}_{0}+F_{1}^{o}\left(\widetilde{h}_{0}\right)-W \widetilde{h}_{0}\right]-\left[Y+W h_{0}^{*}-C_{0}^{*}-F_{1}^{o}\left(h_{0}^{*}\right)\right] .
$$

Now, let

$$
\left(C_{1}^{*}, L_{1}^{*}, h_{1}^{*}\right)=\arg \max _{C, L, h}\left\{\begin{array}{c}
\widehat{U}(C, L): \\
C \leq f(W, Y, h, \theta)-F_{1}^{o}(h)-F_{1}^{u}(h), \\
L=\bar{H}-F_{2}^{u}(h)-F_{2}^{o}(h)-h
\end{array}\right\} .
$$

To evaluate these quantities, note that we can substitute in the time constraint, and use $O=C+F_{1}(h) \Longrightarrow C=O-F_{1}(h)$ to write (122) in an equivalent form as

$$
\left(O_{1}^{*}, h_{1}^{*}\right)=\arg \max _{O, h}\left\{\begin{array}{c}
\widehat{U}\left(O-F_{1}^{u}(h), \bar{H}-F_{2}^{o}(h)-F_{2}^{u}(h)-h\right): \\
O \leq f(W, Y, h, \theta)-F_{1}^{o}(h)
\end{array}\right\}
$$


which can be further rewritten as

$$
\left(O_{1}^{*}, h_{1}^{*}\right)=\arg \max _{O, h}\left\{\widehat{\widehat{U}}\left(O, h+F_{2}^{o}(h)\right): O \leq f(W, Y, h, \theta)-F_{1}^{o}(h)\right\} .
$$

Since $\widehat{\widehat{U}}(a, b)=\overline{\bar{U}}(a, b)$, comparing (124) to (113), it is clear that $O_{1}^{*}=C_{0}^{*}$ and $h_{1}^{*}=h_{0}^{*}$. Letting $u_{1}=U\left(C_{1}^{*}, L_{1}^{*}\right)$, again using the duality between the utility maximization problem and the expenditure minimization problem, we have the vale of the expenditure function evaluated at $u_{1}$,

$$
e\left(W, \theta, u_{1}\right)=Y
$$

Now, let

$$
\left(\widetilde{C}_{1}, \widetilde{L}_{1}, \widetilde{h}_{1}\right)=\arg \min _{C, L, h}\left\{\begin{array}{c}
C+F_{1}^{o}(h)+F_{1}^{u}(h)-W h: \\
\widehat{U}(C, L) \geq u_{1}, L=\bar{H}-F_{2}^{o}(h)-F_{2}^{u}(h)-h
\end{array}\right\} .
$$

Then, by the definition of the expenditure function, we have

$$
e\left(W, u_{1}\right)=\widetilde{C}_{1}+F_{1}^{0}\left(\widetilde{h}_{1}\right)+F_{1}^{u}\left(\widetilde{h}_{1}\right)-W \widetilde{h}_{1} .
$$

Note, however, that since

$$
\begin{aligned}
u_{1} & =\widehat{U}\left(C_{1}^{*}, L_{1}^{*}\right) \\
& =\widehat{U}\left(O_{1}^{*}-F_{1}^{u}\left(h_{1}^{*}\right), \bar{H}-F_{2}^{o}\left(h_{1}^{*}\right)-F_{2}^{u}\left(h_{1}^{*}\right)-h_{1}^{*}\right) \\
& =\widehat{\widehat{U}}\left(O_{1}^{*}, h_{1}^{*}+F_{2}^{o}\left(h_{1}^{*}\right)\right) \\
& =\overline{\bar{U}}\left(C_{0}^{*}, h_{0}^{*}+F_{2}^{o}\left(h_{0}^{*}\right)\right)=u_{0},
\end{aligned}
$$

and using $C=O-F_{1}^{u}(h),(126)$ may be rewritten

$$
\left(\widetilde{O}_{1}, \widetilde{h}_{1}\right)=\arg \min _{O, h}\left\{\begin{array}{c}
O+F_{1}^{0}(h)-W h: \\
\widehat{U}\left(O-F_{1}^{u}(h), \bar{H}-F_{2}^{o}(h)-F_{2}^{u}(h)-h\right) \geq u_{0}
\end{array}\right\},
$$

which, by the definition of $\widehat{\widehat{U}}(O, h)$, becomes

$$
\left(\widetilde{O}_{1}, \widetilde{h}_{1}\right)=\arg \min _{O, h}\left\{O+F_{1}^{o}(h)-W h: \widehat{\widehat{U}}\left(O, h+F_{2}^{o}(h)\right) \geq u_{0}\right\} .
$$

Since $\overline{\bar{U}}(a, b)=\widehat{\widehat{U}}(a, b)$, comparing (130) to $(117)$, it is clear that $\widetilde{O}_{1}=\widetilde{C}_{0}$, and $\widetilde{h}_{1}=\widetilde{h}_{0}$. Using $\widetilde{C}_{1}=\widetilde{O}_{1}-F_{1}\left(\widetilde{h}_{1}\right)$, these equalities imply that (127) is equal to

$$
e\left(W, u_{1}\right)=\widetilde{C}_{0}+F_{1}^{0}\left(\widetilde{h}_{0}\right)-W \widetilde{h}_{0} .
$$

Finally, the tax revenue is

$$
\begin{aligned}
R_{1} & =Y+W h_{1}^{*}-C_{1}^{*}-F_{1}^{o}\left(h_{1}^{*}\right)-F_{1}^{u}\left(h_{1}^{*}\right) \\
& =Y+W h_{1}^{*}-O_{1}^{*}-F_{1}^{o}\left(h_{1}^{*}\right) .
\end{aligned}
$$


which, since $O_{1}^{*}=C_{0}^{*}$ and $h_{1}^{*}=h_{0}^{*}$ as noted above, implies

$$
R_{1}=Y+W h_{0}^{*}-C_{0}^{*}-F_{1}^{o}\left(h_{0}^{*}\right) .
$$

In this case,

$$
D W L_{1}=D W L_{0}=e\left(W, \theta, u_{1}\right)-e\left(W, u_{1}\right)-R_{0}
$$

Substitution of (125), (131), and (134) into (135), and comparing with (121) yields the result.

\subsection{Application to Other Goods}

In order to generalize the deadweight loss equivalence proposition to goods or activities other than labor supply, we need to make a slight adjustment. So, suppose now that a consumer maximizes a utility function over activity or good $x$, other consumption, $C$, and leisure, $L$. Suppose further that consuming activity or good $x$ requires inputs of time, $F_{1}(x)$, and money, $F_{2}(x)$, in order to consume the activity or good. The consumer's problem is then

$$
\begin{aligned}
& \max U(x, C, L) \\
\text { s.t. } p x+F_{1}(x)+C & \leq f(W, Y, h, \theta) \\
L+h+F_{2}(x) & \leq \bar{H} .
\end{aligned}
$$

where $p$ is the price of $x, f(\cdot)$ is the after tax income given gross wage, $W$, nonlabor income, $Y$, hours of work, $h$, and tax parameters, $\theta$, and $\bar{H}$ is the time endowment.

Subbing in the time constraint, and letting $O \equiv C+F_{1}(x)$, this maximization problem may be rewritten as

$$
\begin{aligned}
& \max U\left(x, O-F_{1}(x), \bar{H}-h+F_{2}(x)\right) \\
\text { s.t. } p x+O \leq & f(W, Y, h, \theta)
\end{aligned}
$$

which, defining $\widetilde{U}(x, O, h)=U\left(x, O-F_{1}(x), \bar{H}-h+F_{2}(x)\right)$, can be rewritten as

$$
\begin{aligned}
& \max \widetilde{U}(x, O, h) \\
& \text { s.t. } p x+O \leq f(W, Y, h, \theta)
\end{aligned}
$$

Given this setup, the following proposition, which is analogous to Proposition 8, but concerning the equivalence of deadweight loss due to a tax on the consumption of good $x$, will hold.

Proposition 10 The deadweight loss from an arbitrary income tax schedule $f(W, Y, h, \theta)$ and a tax $t$ on the consumption of good $x$ on an agent with possibly nonconvex preferences $\bar{U}(x, C, L)$, which may be represented in the absence of time and money inputs to the consumption of $x$ as $\overline{\bar{U}}(C, h)=\bar{U}(C, \bar{H}-h)$ equals the deadweight loss from imposing the same taxes on an agent with underlying preferences $\widehat{U}(x, C, L)$ and possibly nonconvex observable preferences $\widehat{\widehat{U}}(x, O, h)=\widehat{U}\left(O-F_{1}(x), \bar{H}-F_{2}(x)-h\right)$, where $\overline{\bar{U}}(a, b, c)=\widehat{\widehat{U}}(a, b, c)$. 
Proof. Consider a choice of consumption, hours of work, and good $x$

$$
\left(x_{0}^{*}, C_{0}^{*}, L_{0}^{*}\right)=\arg \max _{x, C, L}\left\{\begin{array}{c}
\bar{U}(x, C, L): \\
(1+t) p x+C \leq f(W, Y, h, \theta), \\
h=\bar{H}-L
\end{array}\right\},
$$

where $W$ is the gross wage, $Y$ is nonlabor income, $\theta$ are tax parameters, $\bar{H}$ is the time endowment, the price of good $x$ is $p$, and the price of consumption is normalized to 1 . This may be written in an equivalent way as

$$
\left(x_{0}^{*}, C_{0}^{*}, h_{0}^{*}\right)=\arg \max _{x, C, h}\{\overline{\bar{U}}(x, C, h): C \leq f(W, Y, h, \theta)\} .
$$

Let

$$
u_{0}=\bar{U}\left(x_{0}^{*}, C_{0}^{*}, L_{0}^{*}\right)=\overline{\bar{U}}\left(x_{0}^{*}, C_{0}^{*}, h_{0}^{*}\right) .
$$

Using the duality between the utility maximization problem and the expenditure minimization problem, we have the value of the expenditure function evaluated at $u_{0}$,

$$
e\left((1+t) p, \theta, u_{0}\right)=Y \text {. }
$$

Now, let

$$
\left(\widetilde{x}_{0}, \widetilde{C}_{0}, \widetilde{L}_{0}\right)=\arg \min _{x, C, L}\left\{p x+C-W h: \bar{U}(x, C, L) \geq u_{0}, h=\bar{H}-L\right\},
$$

which also has an equivalent formulation as

$$
\left(\widetilde{x}_{0}, \widetilde{C}_{0}, \widetilde{h}_{0}\right)=\arg \min _{x, C, h}\left\{p x+C-W h: \overline{\bar{U}}(x, C, h) \geq u_{0}\right\} .
$$

Clearly, by the definition of the expenditure function,

$$
e\left(p, W h+Y, u_{0}\right)=p \widetilde{x}_{0}+\widetilde{C}_{0}-W \widetilde{h}_{0} .
$$

Finally, let the taxes collected by the government be characterized by $R_{0}$, where

$$
R_{0}=W h_{0}^{*}+Y-f\left(W, Y, h_{0}^{*}, \theta\right)+t p x_{0}^{*} .
$$

By the definition of deadweight loss,

$$
D W L_{0}=e\left((1+t) p, \theta, u_{0}\right)-e\left(p, W h+Y, u_{0}\right)-R_{0} .
$$

Substitution of (139), (142) and (143) into (144) yields

$$
D W L_{0}=Y-\left[p \widetilde{x}_{0}+\widetilde{C}_{0}-W \widetilde{h}_{0}\right]-\left[W h_{0}^{*}+Y-f\left(W, Y, h_{0}^{*}, \theta\right)+t p x_{0}^{*}\right] .
$$

Now, let

$$
\left(x_{1}^{*}, C_{1}^{*}, L_{1}^{*}, h_{1}^{*}\right)=\arg \max _{x, C, L, h}\left\{\begin{array}{c}
\widehat{U}(x, C, L): \\
(1+t) p x+C \leq f(W, Y, h, \theta)-F_{1}(x), \\
L=\bar{H}-F_{2}(x)-h
\end{array}\right\} .
$$


To evaluate these quantities, note that we can use $O=C+F_{1}(x) \Longrightarrow C=O-F_{1}(x)$ and sub in the time constraint to write (146) in an equivalent form as

$$
\left(x_{1}^{*}, O_{1}^{*}, h_{1}^{*}\right)=\arg \max _{x, O, h}\left\{\begin{array}{c}
\widehat{U}\left(O-F_{1}(x), \bar{H}-F_{2}(x)-h\right): \\
(1+t) p x+O \leq f(W, Y, h, \theta)
\end{array}\right\},
$$

which can be further rewritten as

$$
\left(x_{1}^{*}, O_{1}^{*}, h_{1}^{*}\right)=\arg \max _{x, O, h}\{\widehat{\widehat{U}}(x, O, h):(1+t) p x+O \leq f(W, Y, h, \theta)\} .
$$

Since $\widehat{\widehat{U}}(a, b, c)=\overline{\bar{U}}(a, b, c)$, it is clear that $x_{1}^{*}=x_{0}^{*}, O_{1}^{*}=C_{0}^{*}$ and $h_{1}^{*}=h_{0}^{*}$. Letting $u_{1}=\widehat{U}\left(x_{1}^{*}, C_{1}^{*}, L_{1}^{*}\right)$, by definition of the expenditure function, we have

$$
e\left((1+t) p, \theta, u_{1}\right)=Y \text {. }
$$

Now, let

$$
\left(\widetilde{x}_{1}, \widetilde{C}_{1}, \widetilde{L}_{1}, \widetilde{h}_{1}\right)=\arg \min _{x, C, L, h}\left\{\begin{array}{c}
p x+C-W h+F_{1}(x): \\
\widehat{U}(x, C, L) \geq u_{1}, L=\bar{H}-F_{2}(x)-h
\end{array}\right\} .
$$

Then, by the definition of the expenditure function, we have

$$
e\left(p, W h+Y, u_{1}\right)=p \widetilde{x}_{1}+\widetilde{C}_{1}+F_{1}\left(\widetilde{x}_{1}\right)-W \widetilde{h}_{1}
$$

Note, however, that since

$$
\begin{aligned}
u_{1} & =\widehat{U}\left(x_{1}^{*}, C_{1}^{*}, L_{1}^{*}\right) \\
& =\widehat{U}\left(x_{1}^{*}, O_{1}^{*}-F_{1}\left(x_{1}^{*}\right), \bar{H}-F_{2}\left(x_{1}^{*}\right)-h_{1}^{*}\right) \\
& =\widehat{\widehat{U}}\left(x_{1}^{*}, O_{1}^{*}, h_{1}^{*}\right) \\
& =\overline{\bar{U}}\left(x_{0}^{*}, C_{0}^{*}, h_{0}^{*}\right)=u_{0},
\end{aligned}
$$

and using $C=O-F_{1}(x),(150)$ may be rewritten

$$
\left(\widetilde{x}_{1}, \widetilde{O}_{1}, \widetilde{h}_{1}\right)=\arg \min _{x, O, h}\left\{p x+O-W h: \widehat{U}\left(x, O-F_{1}(x), \bar{H}-F_{2}(x)-h\right) \geq u_{0}\right\},
$$

which, by the definition of $\widehat{\widehat{U}}(x, O, h)$, becomes

$$
\left(\widetilde{x}_{1}, \widetilde{O}_{1}, \widetilde{h}_{1}\right)=\arg \min _{x, O, h}\left\{p x+O-W h: \widehat{\widehat{U}}(x, O, h) \geq u_{0}\right\} .
$$

Since $\overline{\bar{U}}(a, b, c)=\widehat{\widehat{U}}(a, b, c)$, it is clear that $\widetilde{x}_{1}=\widetilde{x}_{0}, \widetilde{O}_{1}=\widetilde{C}_{0}$, and $\widetilde{h}_{1}=\widetilde{h}_{0}$. Using $\widetilde{C}_{1}=\widetilde{O}_{1}-F_{1}\left(\widetilde{x}_{1}\right)$, these equalities imply that (151) is equal to

$$
e\left(p, W h+Y, u_{1}\right)=p \widetilde{x}_{0}+\widetilde{C}_{0}-W \widetilde{h}_{0} .
$$


Finally, the tax revenue is

$$
R_{1}=Y+W h_{1}^{*}-f\left(W, Y, h_{1}^{*}, \theta\right)+t p x_{1}^{*},
$$

which, since $h_{1}^{*}=h_{0}^{*}$ and $x_{1}^{*}=x_{0}^{*}$, as noted above, implies

$$
R_{1}=Y+W h_{0}^{*}-f\left(W, Y, h_{0}^{*}, \theta\right)+t p x_{0}^{*} .
$$

In this case,

$$
D W L_{1}=e\left((1+t) p, \theta, u_{1}\right)-e\left(p, W h+Y, u_{1}\right)-R_{1} .
$$

Substitution of (149), (155), and (157) into (158), and comparing with (145) yields the result.

Thus, this proposition demonstrates that in order to calculate the deadweight loss of a on the consumption of good or activity $x$, we do not need to know the form of the time and money costs functions, but rather can simply estimate preferences over good $x$, labor supply $h$, and outlays $O$, and calculate the deadweight loss using these.

For an example of a good to which this proposition would apply, consider the case of golfing. The price of a round of golf is easily observable, but the amount of time it takes is not. In addition, there are some fixed costs to playing golf (buying clubs), and also some marginal costs (replacing broken clubs, replacing balls that are lost, drinks while on the course) that differ depending on how many games are played. This proposition states that, given that one has estimated observable preferences over golf games, hours of work, and other consumption, one could calculate the deadweight loss of a tax on golf without knowing the explicit form of the time and money costs that are involved in playing golf.

\section{References}

[1] Blank, Rebecca M. (1988). "Simultaneously Modeling the Supply of Weeks and Hours of Work among Female Household Heads." Journal of Labor Economics. 6:177-204.

[2] Blau, David M. and Philip K. Robins. (1988). "Child-Care Costs and Family Labor Supply." Review of Economics and Statistics. 70:374-81.

[3] Blomquist, Sören. (1988). "Nonlinear Taxes and Labor Supply." European Economic Review. 31: 1213-1226.

[4] Blomquist, Sören and Urban Hansson-Brusewitz. (1990). "The Effect of Taxes on Male and Female Labor Supply in Sweden." Journal of Human Resources. 25:317-357.

[5] Blundell, Richard and Thomas MaCurdy. (1999). "Labor Supply: A Review of Alternative Approaches." in Handbook of Labor Economics, ed. by O. Ashenfelter and D. Card. New York: North-Holland.

[6] Bourguignon, Francois and Thierry Magnac. (1990). "Labor Supply and Taxation in France." Journal of Human Resources. 25:358-389.

[7] Browning, Martin. (1997). "Interpreting the Results of Empirical Analyses of Intertemporal Allocation: An Identification Problem." Economics Letters. 56:41-44. 
[8] Burtless, Gary and Jerry A. Hausman. (1978). "The Effect of Taxation on Labor Supply: Evaluating the Gary Negative Income Tax Experiment." Journal of Political Economy. 86:1103-1130.

[9] Cogan, John F. (1980). "Labor Supply with Costs of Labor Market Entry." in Female Labor Supply: Theory and Estimation, ed. James P. Smith. Princeton, N.J. : Princeton University Press.

[10] Cogan, John F. (1981). "Fixed Costs and Labor Supply." Econometrica. 49:945-963.

[11] Colombino, Ugo and Daniela Del Boca. (1990). "The Effect of Taxes on Labor Supply in Italy." Journal of Human Resources. 25:390-414.

[12] Feenstra, Robert C. (1986). "Functional Equivalence Between Liquidity Costs and the Utility of Money." Journal of Monetary Economics. 17:271-291

[13] Fortin, Bernard and Guy Lacroix. (1994). "Labour Supply, Tax Evasion and the Marginal Cost of Public Funds: An Empirical Investigation." Journal of Public Economics. 55:407-31.

[14] Fuhrer, Feffrey. (2000). "Habit Formation in Consumption and Its Implications for Monetary-Policy Models." American Economic Review. 90:367-390.

[15] Hall, Robert E. (1973). "Wages, Income and Hours of Work in the U.S. Labor Force." in Income Maintenance and Labor Supply, ed. G. Cain and H. Watts. Chicago: Markham.

[16] Hanoch, Giora. (1980). "Hours and Weeks in the Theory of Labor Supply." in Female Labor Supply: Theory and Estimation, ed. James P. Smith. Princeton, N.J. : Princeton University Press.

[17] Hausman, Jerry A. (1979). "The Econometrics of Labor Supply on Convex Budget Sets." Economics Letters. 3:171-4.

[18] Hausman, Jerry A. (1980). "The Effect of Wages, Taxes and Fixed Costs on Women's Labor Force Participation." Journal of Public Economics. 14:161-194.

[19] Hausman, Jerry. (1981). "Labor Supply." in How Taxes Affect Economic Behavior, ed. H. Aaron and J. Pechman. Washington, D.C.: Brookings Institution.

[20] Hausman, Jerry A. (1985). "Taxes and Labor Supply." in Handbook of Public Economics, ed. by Alan Auerbach and Martin Feldstein. Amsterdam: North-Holland.

[21] Heckman, James J. (1983). "Comment," in Behavioral Simulation Methods in Tax Policy Analysis, ed. by Martin Feldstein, Chicago: University of Chicago Press.

[22] Heim, Bradley T. and Bruce D. Meyer. (2002). "Structural Labor Supply Models when Budget Constraints are Nonlinear." Working Paper.

[23] Hobfoll, Stevan E. (1989). "Conservation of Resources: A New Attempt at Conceptualizing Stress." American Psychologist. 44: 513-524.

[24] Hoynes, Hilary W. (1996). "Welfare Transfers in Two-Parent Families: Labor Supply and Welfare Participation Under AFDC-UP." Econometrica. 64:295-332. 
[25] Juster, F. Thomas and Frank P. Stafford. (1991). "The Allocation of Time: Empirical Findings, Behavioral Models, and Problems of Measurement." Journal of Economic Literature. 39: 471-522.

[26] Lee, Raymond T. and Blake E. Ashforth. (1996). "A Meta-Analytic Examination of the Correlates of the Three Dimensions of Job Burnout." Journal of Applied Psychology. 81: $123-133$.

[27] MaCurdy, Thomas. (1992). "Work Disincentive Effects of Taxes: A Reexamination of Some Evidence." American Economic Review, Papers and Proceedings. 82:243-249.

[28] MaCurdy, Thomas, David Green, and Harry Paarsch. (1990). "Assessing Empirical Approaches for Analyzing Taxes and Labor Supply." Journal of Human Resources. 25:415-490.

[29] Mas-Collel, Andreu, Michael D. Whinston, and Jerry R. Green. (1995). Microeconomic Theory. New York: Oxford University Press.

[30] Morris, J. Andrew and Daniel C. Feldman. (1996). "The Dimensions, Antecedents, and Consequences of Emotional Labor." Academy of Management Review. 21: 986-1010.

[31] Pencavel, John. (1986). "Labor Supply of Men: A Survey." in Handbook of Labor Economics, ed O. Ashenfelter and R. Layard. New York: North-Holland.

[32] Ribar, David C. (1992). "Child Care and the Labor Supply of Married Women: Reduced Form Evidence." Journal of Human Resources. 27:134-165.

[33] Triest, Robert K. (1990). "The Effect of Income Taxation on Labor Supply in the United States." Journal of Human Resources. 25:491-516.

[34] Varian, Hal R. (1992). Microeconomic Analysis: Third Edition. New York: W.W. Norton \& Company. 